\title{
Judged Facial Attractiveness of Extraction and Non-Extraction Orthodontic Treatment in Repose and Smiling
}

Nicolette R. Chahin

West Virginia University, nicolettechahin@gmail.com

Follow this and additional works at: https://researchrepository.wvu.edu/etd

Part of the Orthodontics and Orthodontology Commons

\section{Recommended Citation}

Chahin, Nicolette R., "Judged Facial Attractiveness of Extraction and Non-Extraction Orthodontic Treatment in Repose and Smiling" (2019). Graduate Theses, Dissertations, and Problem Reports. 3925. https://researchrepository.wvu.edu/etd/3925

This Thesis is protected by copyright and/or related rights. It has been brought to you by the The Research Repository @ WVU with permission from the rights-holder(s). You are free to use this Thesis in any way that is permitted by the copyright and related rights legislation that applies to your use. For other uses you must obtain permission from the rights-holder(s) directly, unless additional rights are indicated by a Creative Commons license in the record and/ or on the work itself. This Thesis has been accepted for inclusion in WVU Graduate Theses, Dissertations, and Problem Reports collection by an authorized administrator of The Research Repository @ WVU. For more information, please contact researchrepository@mail.wvu.edu. 


\title{
JUDGED FACIAL ATTRACTIVENESS OF EXTRACTION AND NON-EXTRACTION ORTHODONTIC TREATMENT IN REPOSE AND SMILING
}

\author{
Nicolette Raquel Chahin, D.M.D. \\ Thesis submitted \\ to the School of Dentistry \\ at West Virginia University \\ in partial fulfillment of the requirements for the degree of
}

Master of Science in

Orthodontics

Chris Martin, D.D.S., M.S.
Peter Ngan, D.M.D., Chair
Bryan Weaver, D.D.S., M.D.

Department of Orthodontics

Morgantown, West Virginia

2019

Keywords: facial attractiveness, extraction, non-extraction, repose, smiling Copyright 2019 Nicolette Raquel Chahin, D.M.D. 


\section{ABSTRACT \\ JUDGED FACIAL ATTRACTIVENESS OF EXTRACTION AND NON-EXTRACTION ORTHODONTIC TREATMENT IN REPOSE AND SMILING}

Nicolette Raquel Chahin, D.M.D.

Background and Objectives: More so than ever, the public is becoming exceedingly aware of esthetics, and will evaluate their treatment outcome based upon the improvement to their smile and overall enhancement of their facial appearance. There exists a debate in orthodontics, as to whether or not extractions harm the profile. The aim of this study was to determine if facial attractiveness is harmed in subjects having completed orthodontic treatment involving the extraction of four premolars both in repose and smiling when viewed in lateral profile. Another objective is to identify any impact upper incisor retraction has on facial attractiveness.

Experimental Design and Methods: A sample of 39 subjects that had completed orthodontic treatment (19 extraction subjects and 20 non-extraction subjects) and had existing pre and posttreatment lateral cephalograms, and lateral repose and smiling photographs, were selected.

Orthodontic professionals and laypersons were asked to view a presentation of all of the pre and post-treatment repose and smiling photos of the 39 subjects and asked evaluate facial attractiveness using a visual analogue scale. Amount of incisor retraction was calculated using superimpositions of pre and post-treatment lateral cephalograms. The data was analyzed using paired t-test, ANCOVA, and intra-class correlation coefficient.

Results: For the repose data, a statistically significant difference between the pre-treatment and post-treatment ranking scores $(\mathrm{p}<0.05)$ was observed in 28 of the 39 subjects. 11 of the 39 subjects $(28.2 \%)$ had a positive mean difference in repose. For the smiling data, a statistically significant difference between the pre-treatment and post-treatment ranking scores $(\mathrm{p}<0.05)$ was also observed in 28 of the 39 subjects. 30 of the 39 subjects $(76.9 \%)$ had a positive mean difference in smiling. In repose, no statistically significant difference in attractiveness ranking scores between extraction and non-extraction subjects $(\mathrm{p}>0.05)$ was observed. A significant difference in attractiveness ranking scores between orthodontic professionals and laypersons was observed. Orthodontists gave higher attractiveness ranking scores than laypersons $(\mathrm{p}<0.05)$ Additionally, a significant difference in attractiveness ranking scores among the different levels of retraction was found. Subjects in the $<-2 \mathrm{~mm}$ and $>0 \mathrm{~mm}$ retraction groups were judged to be more attractive than subjects who are in the $-2-0 \mathrm{~mm}$ retraction group $(\mathrm{p}<0.05)$. In smiling, no significant differences were observed for any of the variables, nor when combined.

Conclusions: Extraction therapy is not harmful to the repose profile or the smiling profile. More subjects were judged to be more attractive post-treatment in smiling than repose. Four premolar extraction made the profile more attractive in repose, whenever the incisors were retracted more than $2 \mathrm{~mm}$. Orthodontists gave higher attractiveness ranking scores than laypersons in repose. There are no differences between judged facial attractiveness and non-extraction vs. extraction therapy, orthodontic vs. layperson, or amount of retraction in smiling. 


\section{DEDICATION}

To Nicholas, You are my \#1 constant source of encouragement. You make me strive to be a better person day in, day out. Thank you for being my rock throughout this program. Who would have guessed your broken retainer would get us here.

To Mom and Dad, I would not be where I am without you. Thank you for your endless love and support. You have made me believe that I am capable of accomplishing all of my dreams. And so far, so good! 


\section{ACKNOWLEDGEMENTS}

I would like to bring attention to all of the support, encouragement, and wisdom that has been bestowed upon me throughout my residency. Thank you to all the faculty and staff that have been part of my experience at WVU.

Dr. Ngan, Thank you for being my thesis advisor. You have pushed me constantly to work harder, and for that I am grateful.

Dr. Tremont, You have provided me with the foundation to grow as an orthodontist. Thank you for your patience as you tried to teach me everything you could. You are the epitome of an educator and friend.

Jun Xiang, I am forever indebted to your efforts to analyze the infinite amount of data I presented you with. Thank you for your help.

Dr. Martin, Your willingness to serve this Department does not go unnoticed. Thank you for your clinical guidance and support on this thesis.

Dr. Weaver, Thank you for being on my committee. I appreciate all of your time and your input on this project.

Carl, Marina, and MacKenzie, Your never-ending support and friendship have allowed me to succeed throughout this program. I know that we will remain close throughout our careers, and I look forward growing as orthodontists together.

Stephanie, Sarah, Joanna, Minh, Dustin, Ghady and Mohamad, Thanks for making this program fun. Have confidence in yourselves, because future residents will look up to you more than you know. Best of luck as you finish residency and may you find much success in your future careers. 


\section{TABLE OF CONTENTS}

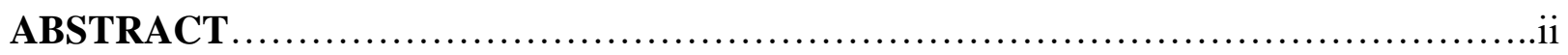

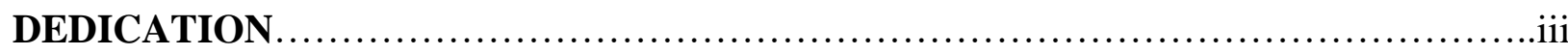

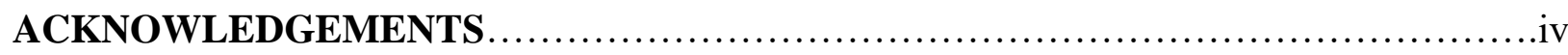

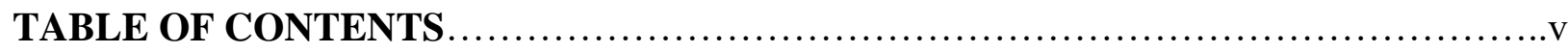

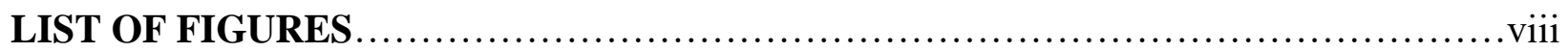

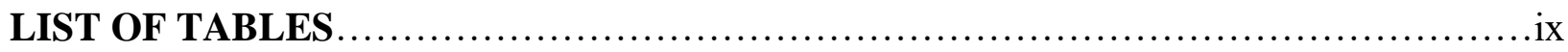

CHAPTER 1: INTRODUCTION

BACKGROUND \& SIGNIFICANCE ...........................................

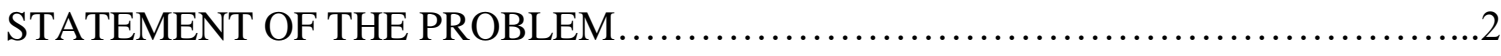

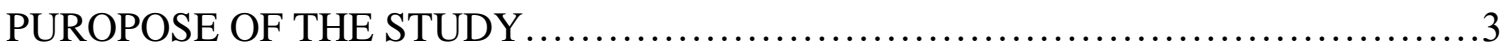

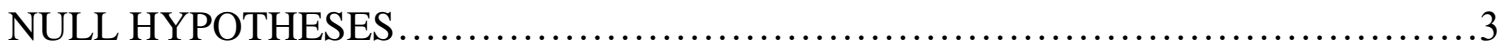

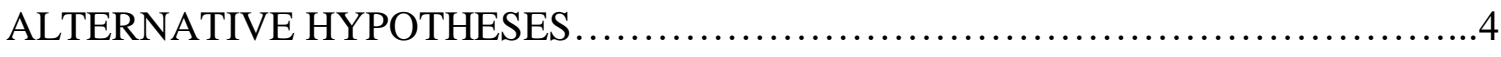

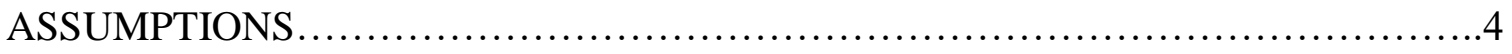

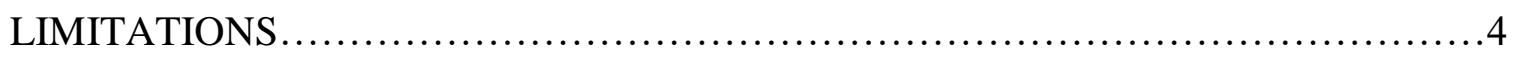

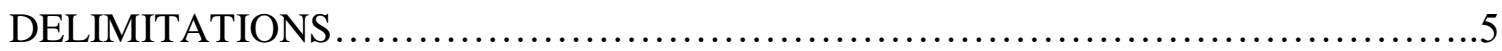

\section{CHAPTER 2: REVIEW OF THE LITERATURE}

SOFT TISSUE PROFILE ESTHETICS AND FACIAL PROPORTION.................6

SMILING ESTHETICS ..................................................

EFFECTS OF UPPER INCISOR POSITION AND INCLINATION ON SMILING

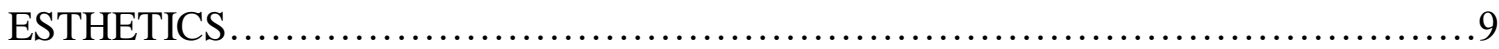

THE SMILING PROFILE................................................. 12

EFFECTS OF EXTRACTION TREATMENT ON FACIAL ATTRACTIVENESS......13 
USING NATURAL HEAD POSITION (NHP) AS STANDARDIZED AND

REPRODUCIBLE POSITION.

USING VISUAL ANALOGUE SCALE (VAS) FOR ESTHETIC EVALUATION OF PROFILES ........................................................................

VARIABILITIES IN JUDGED FACIAL ATTRACTIVENESS.......................18

VARIABILITIES AMONG ORTHODONTIC PROFESSIONALS AND

LAYPERSONS ........................................................................ 19

\section{CHAPTER 3: MATERIALS AND METHODS}

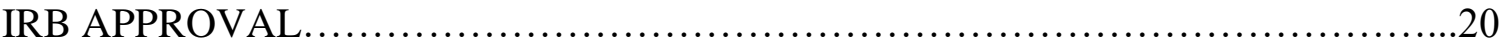

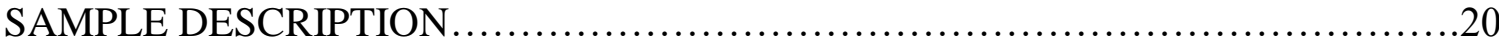

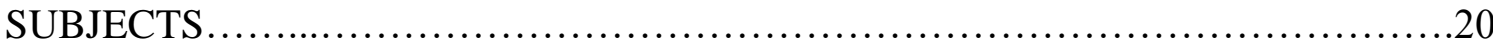

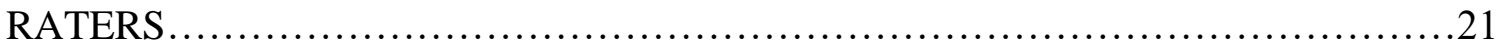

SUBJECT IDENTIFICATION ....................................................

OBTAINING REPOSE AND SMILING PROFILE PHOTOGRAPHS ..................22

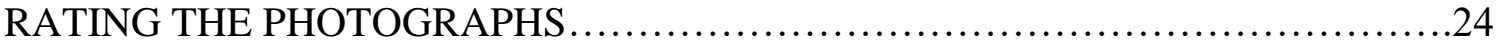

SUPERIMPOSITION OF PRE-TREATMENT AND POST-TREATMENT LATERAL

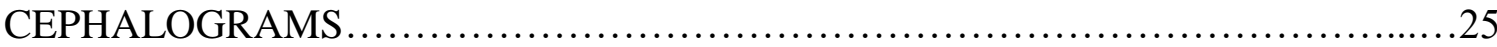

MEASURING AP CHANGE OF UPPER INCISORS ..............................27

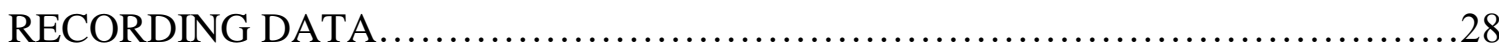

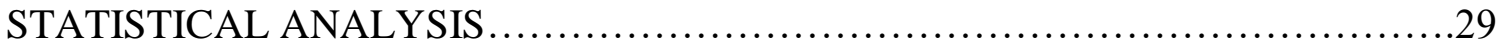

\section{CHAPTER 4: RESULTS}

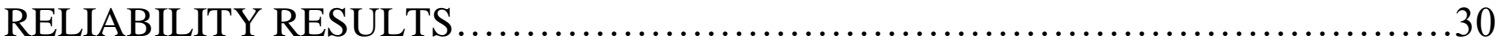

DATA COLLECTION ..........................................................

AMOUNT OF INCISOR RETRACTION ......................................... 31

DIFFERENCE IN PRE AND POST-TREATMENT FACIAL ATTRACTIVENESS IN

REPOSE AND SMILING COMBINED .........................................

DIFFERENCE BETWEEN PRE AND POST-TREATMENT FACIAL ATTRACTIVENESS REPOSE AND SMILING INDEPENDENTLY ...................33

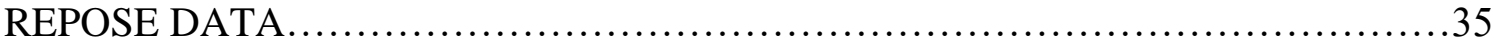




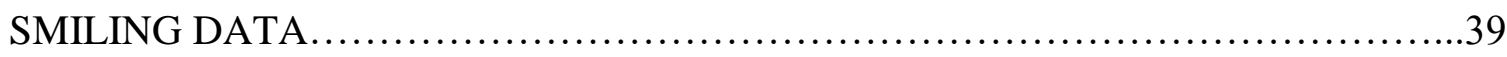

\section{CHAPTER 5: DISCUSSION}

EFFECTS OF EXTRACTION TREATMENT OR INCISOR RETRACTION ON

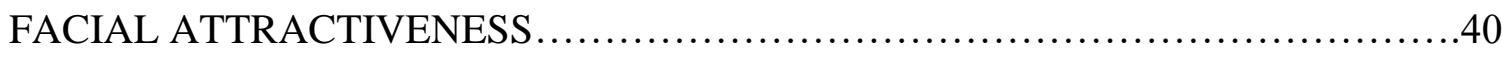

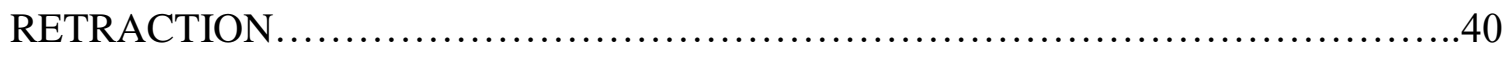

PROFESSIONAL VERSUS LAYPERSON ON JUDGED FACIAL

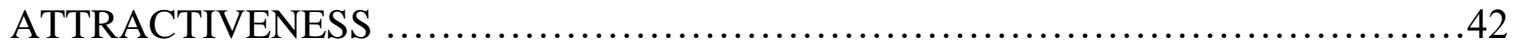

POST-TREATMENT DIFFERENCE IN JUDGED FACIAL ATTRACTIVENESS.....43

VARIABILITY IN RANKING SCORES AMONG JUDGES ON SUBJECTS..........44

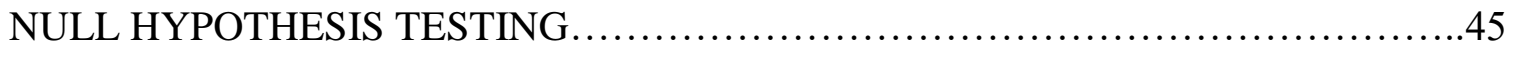

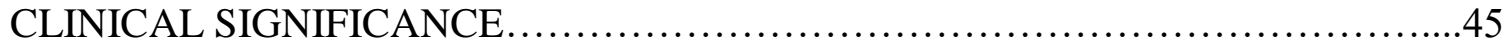

CHAPTER 6: SUMMARY AND CONCLUSIONS

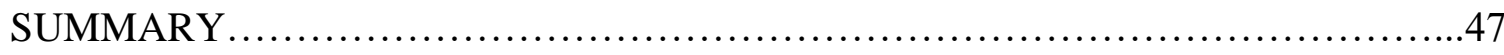

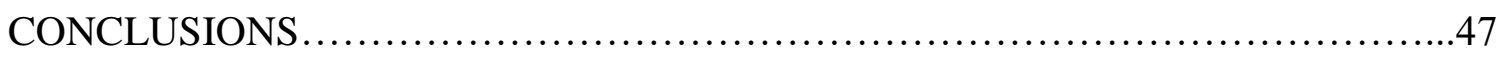

CHAPTER 7: RECOMMENDATIONS FOR FUTURE RESEARCH

RECOMMENDATION ON SAMPLE COLLECTION ...........................48

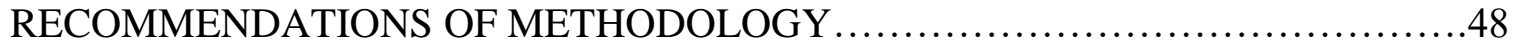

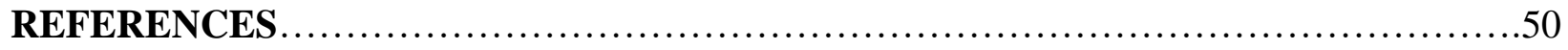

APPENDICES

APPENDIX A - IRB APPROVAL LETTER .......................................54

APPENDIX B - VISUAL ANALOGUE SCALE SURVEY SAMPLE...................56 


\section{LISTS OF FIGURES}

Figure 1: Evaluation of lip prominence...................................................

Figure 2: Facial Axis Point........................................................ 11

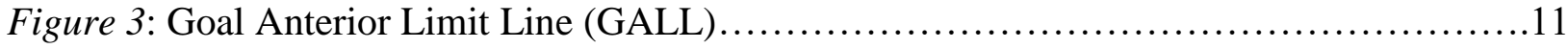

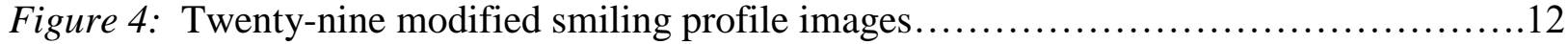

Figure 5: Example Photo Montage taken from ABO website...........................13

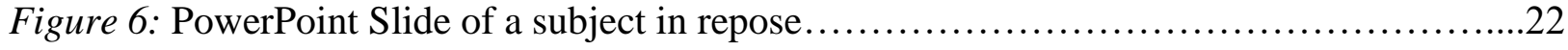

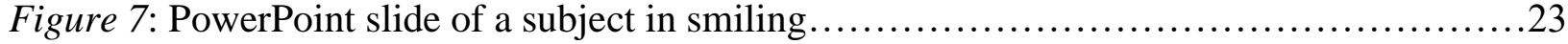

Figure 8: Two visual analogue scales provided for each PowerPoint slide..................24

Figure 9: Digitization of lateral cephalogram in Dolphin Imaging ........................25

Figure 10: Superimposition of pre-treatment and post-treatment lateral cephalograms..........26

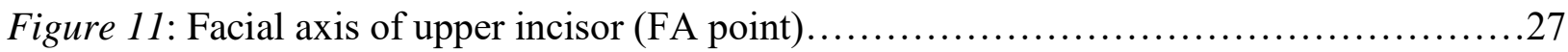

Figure 12: Measuring points and lines used for calculating AP change of upper incisors........28

Figure 13: Means of difference for Repose and Smiling .................................

Figure 14: LS Means for Retraction Level.............................................. 37

Figure 15: LS Means for Orthodontic Professionals and Laypersons......................... 38 


\section{LIST OF TABLES}

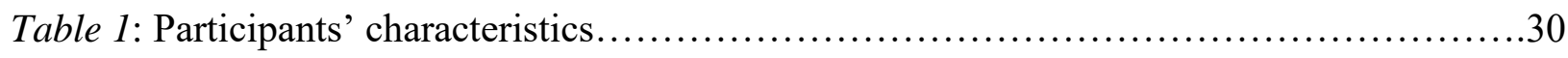

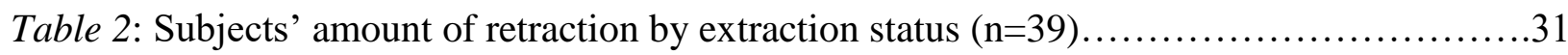

Table 3: Difference between pre and post-treatment ranking scores of all subjects..............32

Table 4: Difference between pre and post-treatment ranking scores for repose and smiling

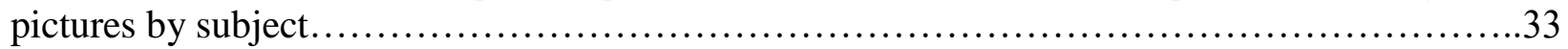

Table 5: ANCOVA analysis for association between facial attractiveness and extraction status (model 1), group (model 2), retraction level (model 3), all variables (model 4) adjusted for preattractiveness ranking score for repose data............................................

Table 6: Least Square means comparison for retraction level and group for repose data.........37

Table 7: ANCOVA analysis for association between facial attractiveness and extraction status (model 1), group (model 2), retraction level (model 3), all variables (model 4) adjusted for preattractiveness ranking score for smiling data.......................................... 39 


\section{CHAPTER 1: INTRODUCTION}

\section{BACKGROUND \& SIGNIFICANCE}

"Beauty is in the eye of the beholder," is an age-old saying, which suggests that attractiveness may be somewhat subjective. However, there is evidence that some individuals can be universally regarded as attractive, and that people can agree on attractiveness. Thus, facial attractiveness cannot be completely subjective, and there may be certain features of the face that contribute to facial attractiveness. ${ }^{1}$ Lips, eyes, teeth, and cheeks have been studied in facial attractiveness. Besides facial features, many other elements can influence the attractiveness of the face. Examples include cultural, genetic, and environmental factors. These elements are out of the orthodontist's control. It is important to recognize, however, that a planned orthodontic treatment does not simply affect the teeth, but the face as a whole. Facial attractiveness should be taken into consideration when planning orthodontic treatment, and how it will affect the face.

The ongoing extraction versus non-extraction debate is ever prevalent in the orthodontic literature and community. Proponents of non-extraction therapy presume that extraction therapy results in a "dished in face." Meanwhile, advocates of extraction therapy tout that the excessive proclination of upper incisors "blows out the lips." Interestingly, these assertions have been based upon evaluation of the face in a repose profile view. The soft tissue drape is relied upon to identify the relationship of the incisors to the face, despite the potential unpredictability of this method. ${ }^{3}$ When evaluating the attractiveness of the smile, contemporary orthodontic diagnosis typically assesses the smile from a frontal view. Limited research has been conducted on the smiling profile, and furthermore, no research has been conducted on the attractiveness of the smiling profile in cases treated with four premolar extraction therapy versus non-extraction 
therapy. Presently, orthodontic literature offers different methods for evaluating the anteroposterior (AP) position of the upper incisors. Dr. Lawrence Andrews suggests the use of a smiling profile to determine the positon of the maxilla and maxillary incisors. ${ }^{4}$ His Six Elements Philosophy goals include a harmonious anteroposterior relationship between the forehead (glabella) and the upper incisors. ${ }^{5}$ Schlosser et al. found this method of profile assessment to be "a useful method to evaluate attractiveness relative to the maxillary incisor position." 6

There have been no studies that attempt to determine if facial attractiveness is harmed in patients having completed orthodontic treatment involving the extraction of four premolars both in repose and smiling when viewed in lateral profile. Additionally, there is a need for more literature on the impact upper incisor retraction has on facial attractiveness.

The effect of orthodontic training and different views of the face presented as a stimulus for this study on judged facial attractiveness. More so than ever, the public is becoming exceedingly aware of esthetics, and will evaluate their treatment outcome based upon the improvement to their smile and overall enhancement of their facial appearance. ${ }^{7}$ Thus, a study using this design could affect ultimate treatment decisions. Because lay people and orthodontists will participate in the study, societal and professional opinions on facial attractiveness will be made. The information revealed in this study mas assist orthodontists in making recommendations and treatment planning decisions.

\section{STATEMENT OF THE PROBLEM}

There exists a debate in orthodontics, as to whether or not extractions harm the profile. No studies have been conducted that evaluate the judged facial attractiveness of non-extraction therapy versus four premolar extraction therapy in repose and smiling profile photographs. 
Additionally, no studies have been conducted that correlate judged facial attractiveness with how much the upper incisors have been retracted.

\section{PURPOSE OF THE STUDY}

- To determine if there is a difference in the judged facial attractiveness between the nonextraction and four premolar extraction groups repose profiles

- To determine if there is a difference in the judged facial attractiveness between the nonextraction and four premolar extraction groups smiling profiles

- To determine if there is a correlation between the degree of upper incisor retraction and the judged facial attractiveness in the repose and smiling profiles

- To determine if there is a difference in the judged facial attractiveness between the orthodontic professionals and the laypersons

\section{NULL HYPOTHESES}

1. There is no difference in the judged facial attractiveness between the non-extraction and four premolar extraction groups repose profiles

2. There is no difference in the judged facial attractiveness between the non-extraction and four premolar extraction groups smiling profiles

3. There is no correlation between the degree of upper incisor retraction and the judged facial attractiveness in the repose and smiling profiles

4. There is no difference in the judged facial attractiveness between the orthodontic professionals and the laypersons 


\section{ALTERNATIVE HYPOTHESES}

1. There is a difference in the judged facial attractiveness between the non-extraction and four premolar extraction groups repose profiles

2. There is a difference in the judged facial attractiveness between the non-extraction and four premolar extraction groups smiling profiles

3. There is a correlation between the degree of upper incisor retraction and the judged facial attractiveness in the repose and smiling profiles

4. There is a difference in the judged facial attractiveness between the orthodontic professionals and the laypersons

\section{ASSUMPTIONS}

1. The investigator can reliably and consistently orient profile photos in adjusted upright head posture

2. The investigator can reliably and consistently superimpose lateral cephalograms in a 1:1 ratio

\section{LIMITATIONS}

1. Other facial features may influence rater's judgment of subjects' attractiveness

2. Potential for growth or adverse effects of aging between pre-treatment and post-treatment photos may influence raters' judgment of subjects' attractiveness

3. The majority of faculty/orthodontic residents have been trained to evaluate the AP position of the maxillary incisors 


\section{DELIMITATIONS}

1. Subjects with both upper and lower premolar extractions included in four premolar extraction group

a. Upper premolar extractions only cases will have upper incisor position dictated by position of lower incisor

b. No distinction as to which premolars (first premolars versus second premolars, or a combination) were extracted in the four premolar group was made

2. Both groups will consist of subjects with various malocclusions, but with positive overjet (i.e. Class I, II, and III with positive overjet). 


\section{CHAPTER 2: REVIEW OF THE LITERATURE}

\section{SOFT TISSUE PROFILE ESTHETICS AND FACIAL PROPORTION}

Although facial proportions vary with age, sex, and race, it is worthwhile to identify esthetic norms or ideals when analyzing the face in profile. ${ }^{8}$ Vertical facial proportions can be observed with a patient in profile view. Renaissance artists da Vinci and Durer established the ideal proportions of a balanced profile. Thus, an anatomically correct face can be divided into three regions, all being equal in length. ${ }^{9}$ The three thirds of the face include the distance from trichion to glabella, glabella to subnasale, and subnasale to menton. These standards continue to be recognized today in art and orthodontics. Additionally, the lower third of the face can be divided into thirds as well. The mouth ideally is located one third of the way from subnasale to menton. Supplementary information that can be gathered when viewing the face in profile view is the inclination of the mandibular plane. A steeper mandibular plane will often yield a long anterior facial dimension. Conversely, a flat mandibular plane angle often correlates with a shorter anterior facial height.

In a lateral view, the nose is a significant component of the midface. The radix, which is the depth of the concavity at the base of the forehead, should block the eyelash on the other side when viewed in profile. The nasal dorsum idyllically is a straight line from the radix to the nasal tip. At this point, the tip becomes slightly more prominent than the dorsum. Furthermore, the paranasal regions of the maxilla are slightly convex and partially conceal the alar base. A deficiency in this area is often present in patients with a maxillary deficiency, and may make the nose look larger than it is because little to none of the nose is concealed. ${ }^{10}$ 
A discussion of lip posture goes hand in hand with incisor prominence. A dental arch with protruded upper incisors affects the amount of space located within the arch. Protruded upper incisors may be well aligned, but at the expense of the position of the upper lip. The upper lip with significantly protruded upper incisors will protrude and make it difficult for the patient to bring the lip into function over the protruded teeth. According to Proffit, determining whether the upper incisors are excessively proclined can be decided by two factors: 1) the lips are prominent and everted and 2) the lips are separated at rest by more than 3-4 mm (lip incompetency). ${ }^{11} \mathrm{~A}$ patient presenting with both of these factors must strain to bring the lips together over excessively proclined upper incisors. Retracting the protruded teeth would improve facial esthetics and lip function in such a patient. Lip posture and incisor prominence should be evaluated in a lateral view with the patient's lips in a relaxed state. In the presence of lip incompetency, lips that protrude more than 2-3 $\mathrm{mm}$ beyond true vertical lines through soft tissue points $\mathrm{A}$ and $\mathrm{B}$ indicate incisor protrusion. Often times, it is useful to use the E-line because observers perceive lip posture with respect to the nose and chin. This is depicted in Figure X, taken from Proffit. ${ }^{12}$ Ideally, the lower lip is $2 \pm 2 \mathrm{~mm}$ to the E-line, and the upper lip is $4 \pm 2$ mm. 


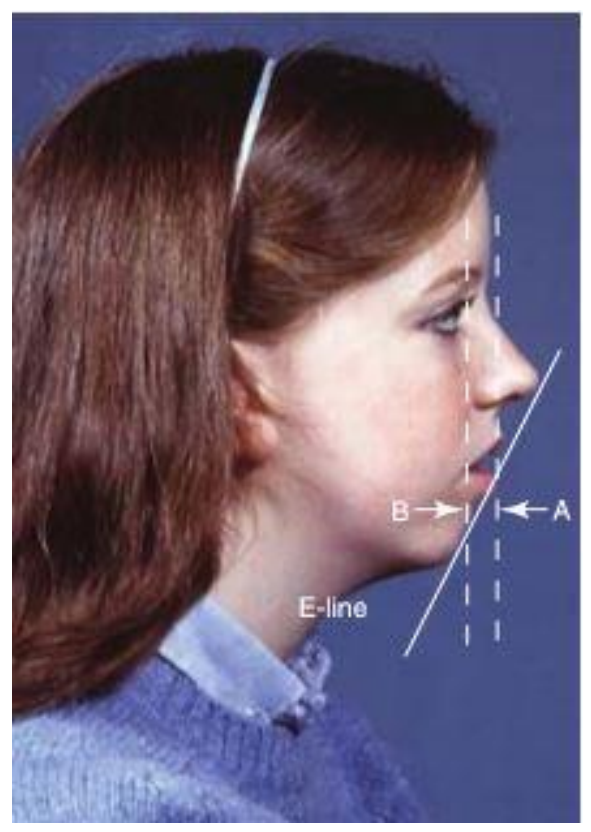

Figure 1: Evaluation of lip prominence

Lastly, the presentation of the throat can be defined by various angles. The lip-chin-throat angle is formed by the lower lip, chin, and the point at the deepest part of the concavity along the chinneck contour. This angle ideally is $90^{\circ}$. As this angle becomes more obtuse, the profile is seen as less esthetic, and can be caused by a deficient chin, retrognathic mandible, excessive submental fat, or lower lip procumbency. Another angle, the chin-neck angle, has been described to ideally be $90^{\circ}$ for proper esthetics. ${ }^{13}$ However, values between $105-120^{\circ}$ are also considered as normal. The more obtuse this angle, the less esthetic the profile becomes. Age, weight gain, and submental fat deposition are factors that can increase this angle. The last angle of interest when describing ideal throat form is the chin-throat length. This distance is measured from soft tissue pogonion to the deepest part of the concavity along the chin-neck contour. No normal value exists for chin-throat length, however, in a patient with a mandibular deficiency and obtuse chinneck angle, lengthening the chin-throat length with a mandibular advancement can contribute to the esthetic improvement of the lower face. ${ }^{14}$ 


\section{SMILING ESTHETICS}

A smile is one the most important facial expressions. It is a critical component in the expression of gratitude, happiness, approval, and friendliness. ${ }^{15}$ Recently, smile esthetics have become exceedingly more important for orthodontists because more orthodontic patients evaluate the outcome of treatment by the improvement of their smiles and overall enhancement of their facial appearance. Orthodontic treatment has historically been based primarily on the improvement of occlusal relationships. Presently, one of the major goals of orthodontics is to enhance the appearance of the anterior tooth display during smiling and speech. ${ }^{16}$ Today, more attention is being given to striving for optimal facial esthetics, with the enhancement of dentofacial characteristics. ${ }^{17}$

\section{EFFECTS OF UPPER INCISOR POSITION AND INCLINATION ON SMILING ESTHETICS}

When the American Journal of Orthodontics was commissioned in 1915, scientific treatment goals did not exist. Uncertainties in the field promoted Dr. Lawrence Andrews to dedicate himself to identifying treatment goals, classification, and rules for orthodontic treatment. From 1960-1964, Andrews collected a sample of 120 casts of non-orthodontic patients with what was described as normal occlusion. According to Andrews, the models that were selected were "of teeth which (1) had never had orthodontic treatment, (2) were straight and pleasing in appearance, (3) had a bite which looked generally correct, and (4) in my judgment would not benefit from orthodontic treatment." ${ }^{\prime 18}$ The models were studied and characterized to assess common characteristics. Six were identified, and called the six keys to normal occlusion. ${ }^{19}$

In the 1980s, Andrews continued his research to satisfy his yearning for scientific treatment goals for anteroposterior tooth and jaw positions. Over 1000 profile images of persons judged to 
have facial harmony were studied. This data, combined with the information provided from the sample of 120 casts, led to the identification of six areas in which orthodontists have diagnostic responsibility, known as the Six Elements. The Six Elements include: (I) optimal tooth and arch characteristics, (II) optimal AP jaw positions, (III) optimal jaw widths, (IV) optimal jaw heights, (V) optimal chin prominence, and (VI) optimal occlusion. ${ }^{20}$

Element II communicates optimal AP jaw positions. Andrews describes the goal anterior limit line (GALL), which is used to evaluate the anteroposterior position of the maxillary incisors from a smiling profile perspective. GALL is a frontal plane of the face, which represents the anterior limit of the maxillary incisors. The relationship is quantified as a millimeter measurement between the FA point (point on the facial axis that separates the gingival and incisal halves of the clinical crown) of the maxillary incisor crown and the GALL line. The anteroposterior position of the maxilla is optimal when maxillary incisors are at the optimal inclination and position in basal bone, along the GALL. ${ }^{21}$ 


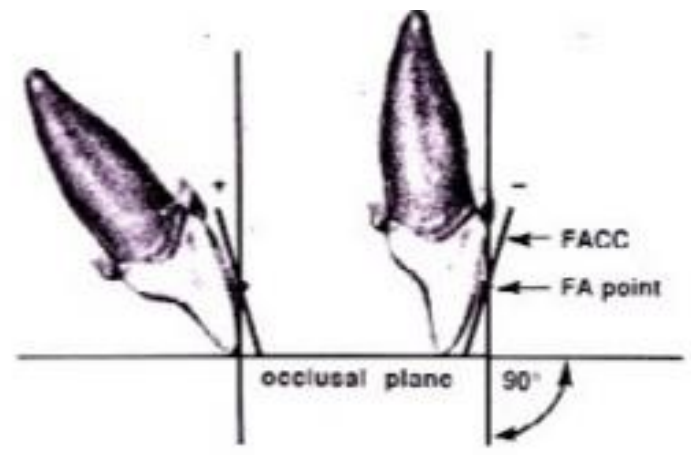

Figure 2: Facial Axis Point

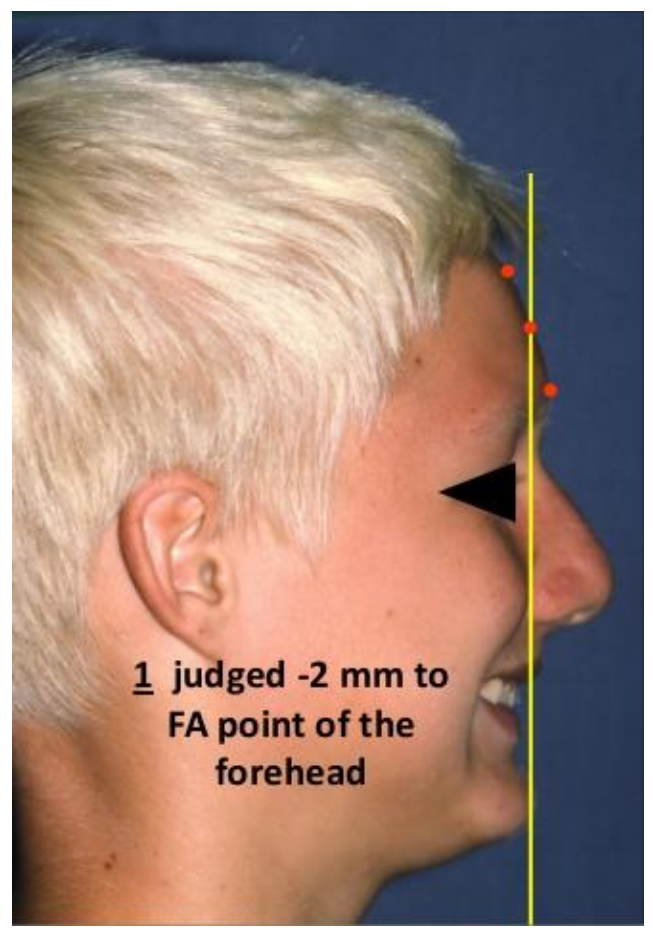

Figure 3: Goal Anterior Limit Line (GALL)

Schlosser et al. concluded that Andrews' method of profile assessment was a "useful method to evaluate attractiveness relative to the maxillary incisor position.” Research by Tomblyn et al. found GALL was a reliable and reproducible reference plane. The GALL line is a landmark and FA points on the maxillary incisors are referents. They also determined that GALL can be used as a frontal plane for diagnosis and treatment planning. ${ }^{22}$ Inclusion of this criteria in diagnosis and treatment planning should be critical to the orthodontist, because patients are exceedingly cognizant of how they look. ${ }^{23}$ Attractive facial esthetics is undoubtedly a major treatment goal of orthodontics. When seeking orthodontic treatment, a patient may desire an improvement in function, yet, an esthetic improvement may also be obligatory. 


\section{THE SMILING PROFILE}

Facial morphology can be analyzed clinically through the use of photographs. This approach is valid in assessing smile traits and facial attractiveness. ${ }^{24}$ Currently, there are few studies that have been completed on esthetics of the smiling profile. Within current literature exists a study completed by Cao et al, which investigated the effect of maxillary incisor labiolingual inclination and anteroposterior position on smiling profile esthetics. The study modified a facial smiling profile photograph of a Chinese woman with a normal Class I occlusion, skeletal pattern, and profile to produce twenty-nine smiling profile images. The images varied in AP position and labiolingual inclination of the maxillary incisors.
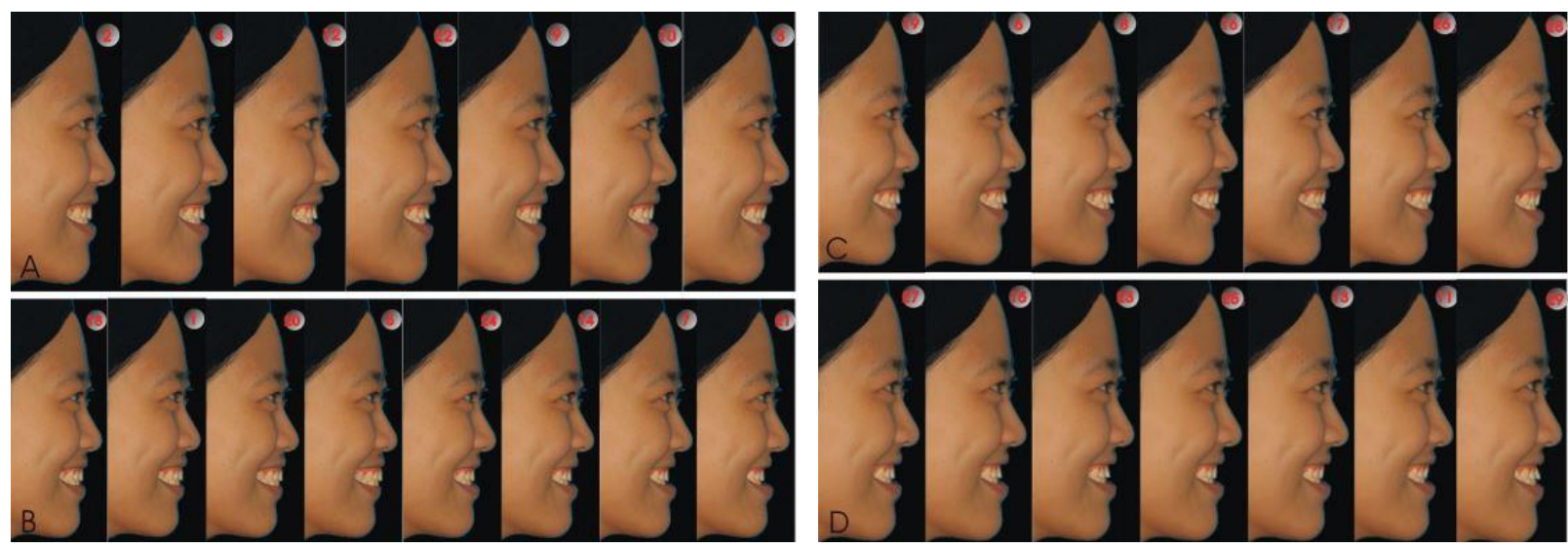

Figure 4: Twenty-nine modified smiling profile images

With regard to the AP position of the maxillary incisors, attractiveness of the profiles was reduced with incisor retrusion. All images with $2 \mathrm{~mm}$ retrusion were considered unattractive, regardless of the labiolingual inclination. ${ }^{25}$ Another study completed by Schlosser et al. that evaluated the AP position of the maxillary incisor concluded that protrusion of the upper incisors 
was more attractive than retruded incisors from an esthetic standpoint. ${ }^{26}$ In consequence, the limited research on the smiling profile trends to agree on retruded incisors being less attractive.

Interestingly enough, even as facial esthetics becomes a more important objective in orthodontics, the American Board of Orthodontics $(\mathrm{ABO})$ currently requires only three facial photos for an ideal photo montage for board certification. The three photos are a lateral view in repose, a frontal view in repose, and a frontal view in smiling.
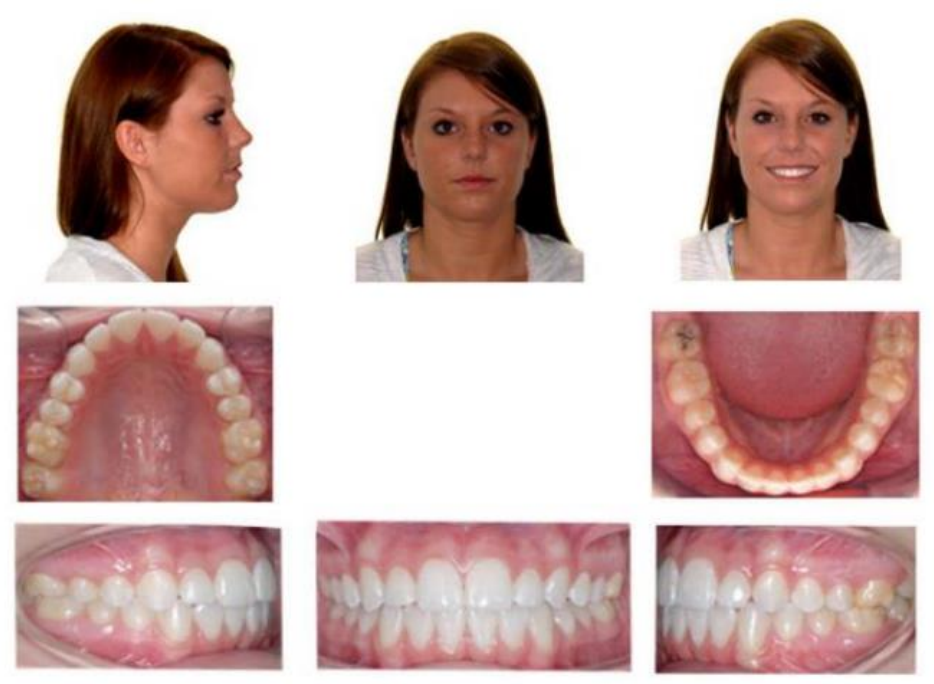

Figure 5: Example Photo Montage taken from ABO website

\section{EFFECTS OF EXTRACTION TREATMENT ON FACIAL ATTRACTIVENESS}

The extraction versus non-extraction debate, ongoing for almost 100 years, has often been based more on assumption rather than fact. ${ }^{27}$ Those who favor non-extraction have often presumed that 
extraction treatment tends to dish in the face; those who favor extraction the other hand, often presume the lips tend to be blown out by excessive incisor flaring.

Recently, Işiksal compared smile esthetics of extraction and non-extraction patients and a control group. This research is timely because some practitioners believe that extractions result in large buccal corridors that are detrimental to the smile. In that study, the smiles were evaluated in a frontal view by 10 orthodontists, 10 plastic surgeons, 10 general dentists, 10 artists, and 10 patients. They concluded that there was no difference in attractiveness between the extraction group, non-extraction group, or the control group. They did find that the extraction group actually had wider arches than the non-extraction group when measured with a digital caliper, thus challenging the belief that extractions lead to a narrower smile. ${ }^{28}$ An important discovery in this study was found among the cephalometric numbers of the subjects. The extraction group was found to have a statistically significant different U1-SN angle compared to the other groups. The upper incisors in this group seemed to need more labial crown torque after retraction. However, this did not affect the ultimate smile esthetics among the three groups, yet it is important for orthodontists to place the upper incisors in a favorable anteroposterior and vertical relationship to within the face, to ensure satisfactory facial harmony. ${ }^{29}$ This result is consistent with a previous study by Meyer, which reported that although significant arch width changes were possible to occur with extraction therapy, no clinically relevant effects on the buccal corridor ratio were identified. ${ }^{30}$

How extraction versus non-extraction therapy affects the profile also is of particular interest. As previously mentioned, extraction therapy has often been believed to be detrimental to the profile. This is important because if a patient has proclined incisors or proclined incisors with crowding, it would be virtually impossible to improve the anteroposterior position of the teeth and the 
patient's profile without incorporation of extractions into the treatment plan. Bowman and Johnston investigated the profile changes in extraction and non-extraction patients when assessed by laypersons and dentists. It was concluded that extraction therapy had a positive effect on the profile of patients with some combination of crowded and proclined teeth, whereas nonextraction therapy was seen as having little effect on the profile. ${ }^{31}$ The improvement of the profile in the extraction group was directly proportional to the subject's initial lip procumbency. The extractions helped protrusive profiles, but hurt retrusive profiles. Thus, they concluded that extraction therapy can benefit the patient when the objective is to reduce lip procumbency.

While some orthodontists will continue to claim that extractions are detrimental to the profile, the question arises if the general public is sensitive to any dental or facial changes brought about with extraction therapy. Bishara and Jakobsen randomly presented extraction and non-extraction profile silhouettes of pretreatment and post treatment patients to laypersons. Their findings demonstrated that the general public does not prefer the profiles of 1 group over the other. ${ }^{32}$ A systematic review by Almurtadha et al. concluded that an increase in the nasolabial angle and significant retraction of the lips are associated with extraction therapies, however, the degree to which these changes are considered to be detrimental to the profile is affected by numerous factors. ${ }^{33}$ They recommend that whenever extraction therapy is indicated, the suspected soft tissue changes should be evaluated to see if the changes would be favorable or unfavorable. The findings of their research were of moderate quality, so further research was recommended. 
USING NATURAL HEAD POSITION (NHP) AS STANDARDIZED AND REPRODUCIBLE POSITION

Traditionally, intracranial reference planes have been used for the cephalometric diagnosis and treatment planning of orthodontic cases. However, the validity of intracranial reference planes like Frankfort Horizontal (FH) and Sella Nasion (SN) has been questioned due to the variability of the horizontal plane, related to natural head position (NHP). ${ }^{34}$ Natural head position (NHP) has been described as a "standardized and reproducible position, of the head in an upright posture, the eyes focused on a point in the distance at eye level, which implies that the visual axis is horizontal." Anthropologists, artists, and anatomists have use NHP to study the face for ages. ${ }^{35}$ Upon the introduction of cephalometric radiology, there was a need for a standardized and reproducible head position, that would allow for orthodontic cephalometric evaluation. There existed a belief that the alignment of the cervical column, natural body posture, and natural head position were reproducible. The concept of a NHP was introduced to orthodontics in the 1950's. Furthermore, NHP has been used for clinical examination in medicine, dentistry, plastic surgery, and oral maxillofacial surgery. ${ }^{36}$

NHP reproducibility refers to how consistently a subject can reproduce the same head position at different time points. Pereira et al. conducted a study that assessed the reproducibility of natural head position (NHP) in children. Profile photographs were taken in NHP with and without the aid of a cephalostat at two time intervals ( $\mathrm{t}=0$ days and $\mathrm{t}=15$ days). The study concluded that there were no significant differences in NHP over the 15-day interval with or without the use of a cephalostat, thus proving NHP to be a reproducible method. ${ }^{37}$ Lundstrom found NHP reproducibility to be close to $2^{0 .}{ }^{38}$ These findings, along with the fact that NHP depicts a realistic appearance of patients, support its use in cephalometric analysis. Long term research by Cooke el 
al. at 5 year and 15 year time points reported $3.04^{\circ}$ and $2.20^{\circ}$ variations respectively. These values are significantly less than the variance of intracranial reference planes to the vertical (25$\left.36^{0}\right) .{ }^{39}$ Thus, cephalometric analysis of NHP remain valid over time.

Regardless of being reliable and reproducible, NHP may contain an element of unavoidable error that requires correction. This leads to the introduction of adjusted natural head position (adjusted NHP). It is defined as the head position adjusted from the registered natural head position to a position judged to be the natural head orientation by the orthodontist. ${ }^{40}$ This distinction, of being attuned by the orthodontist, is important because the orthodontist is responsible for deriving a diagnosis and establishing a treatment plan, while using a valid craniofacial reference system.

\section{USING VISUAL ANALOGUE SCALE (VAS) FOR ESTHETIC EVALUATION OF PROFILES}

The Visual Analogue Scale (VAS) is a measurement tool that measures a certain characteristic or attitude that is believed to exist along a continuum of values, that would otherwise prove difficult to directly measure. It is often used in clinical research and epidemiologic studies to evaluate the frequency or intensity of various symptoms. ${ }^{41}$ The VAS is simple and inexpensive, which makes it one of the most widely used methods for esthetic evaluations of profiles, incisor position, and post-treatment evaluations. In the UNC study by Phillips et al., which involved rating of facial attractiveness, the visual analogue scale was deemed straightforward and acceptable to panels of orthodontic residents, dental students, and laypersons. It proved to be a rapid method to obtain a large number of scores on facial attractiveness. ${ }^{42}$ 


\section{VARIABILITIES IN JUDGED FACIAL ATTRACTIVENESS}

A standard yardstick does not exist for determining facial attractiveness. Are orthodontists attempting to make a scientific proposition out of what can only be a matter of personal taste? Is beauty truly in the eye of the beholder? Equal amounts of studies that reveal agreement on the perception of attractiveness are matched with just as many studies that show inconclusiveness. Physical attractiveness does indeed carry social consequences. Attractive persons are perceived to possess a variety of positive personality attributes like experiencing success with work and dating, and even financial wealth. ${ }^{43}$ Despite research on social consequences, exactly what makes a face beautiful is not clearly defined. ${ }^{44}$ Variability can exist in judged facial attractiveness among dentists and laypersons, males and females, and among different ethnicities and races. A dentist's educational background and training will surely influence his or her preferences in treatment planning. Foster conducted a study in which the silhouette of a Caucasian female was altered to produce seven images of varying lip protrusion. The images were presented to white, black, and Chinese lay groups, as well as to a panel of professionals consisting of general dentists, orthodontists, and art students. The judges were asked to identify the most pleasing silhouette for various age groups. All of the groups preferred adult females to have $3 \mathrm{~mm}$ fuller lips compared to adult males, except the group of orthodontists, who preferred fuller lips by only $1.4 \mathrm{~mm}$. Furthermore, all groups preferred fuller lips for younger ages. ${ }^{45}$ Thus, it is transparent that while there can be agreement among groups, variability can still exist. 


\section{VARIABILITIES AMONG ORTHODONTIC PROFESSIONALS AND LAYPERSONS}

Laypersons are being influenced by the media and seek to conform to esthetic ideals seen on television and the internet. Online, there has been an increase in the number of searches for surgical and esthetic treatments in dentistry. ${ }^{46}$ Of curiosity is whether orthodontists and laypersons tend to agree on what an attractive treatment outcome or facial appearance is. A study by Barbosa de Lima et al. assessed the influence of facial pattern in smile attractiveness by using frontal images with modified levels of gingival exposure in balanced and long-face subjects. The raters were laypersons and other dental professionals (orthodontists, oral surgeons, and

periodontists. $)^{47}$ Laypersons were less critical than dental specialists. Laypersons were also more tolerant of excessive gingival exposure in a balanced-face subject. However, both groups were more critical of the long-faced subject at all levels of gingival exposure. Thus, here does seem to be some agreement in smile attractiveness in this study. Another study by Giron de Velasco et al. investigated the effect of various incisor torque on modified profile photos of a 30-year-old woman. ${ }^{48}$ They found orthodontists were less tolerant of retroclined incisors and preferred protrusive torques in comparison to laypersons. 


\section{CHAPTER 3: MATERIALS AND METHODS}

\section{IRB APPROVAL}

Approval for expedited research was obtained from West Virginia University Institutional Review Board (1805113206) prior to the start of this study. See Appendix A.

\section{SAMPLE DESCRIPTION}

There were 39 subjects and 32 raters in this study. The subjects included 20 completed nonextraction therapy cases and 19 completed four premolar extraction cases. The raters included 16 orthodontic faculty members/residents and 16 laypersons.

\section{SUBJECTS}

Inclusion Criteria

- Orthodontic treatment completed either with non-extraction therapy or with four premolar extraction therapy

- Subjects must have a pre-treatment and post-treatment lateral cephalogram

- Subjects must have pre-treatment and post-treatment adjusted natural head position profile photos taken in repose and smiling

\section{Exclusion Criteria}

- Craniofacial abnormalities

- Severely rotated maxillary incisors 


\section{RATERS}

Inclusion Criteria

- West Virginia University School of Dentistry orthodontic faculty or resident

- Non-orthodontic professional ( $1^{\text {st }}$ year West Virginia University School of Dentistry student), also known as a layperson

- HIPAA training

\section{SUBJECT IDENTIFICATION}

The 39 subjects for this study were selected from West Virginia School of Dentistry Orthodontic Department. 20 randomly selected completed non-extraction therapy cases and 19 randomly selected completed four premolar extraction cases were identified as the subjects.

The prospective raters included 16 non-orthodontic professionals with previous HIPAA training and 16 West Virginia University School of Dentistry orthodontic faculty members/residents. A power sample size estimator was used to identify the number of raters needed for the study. The non-orthodontic professionals were engaged using a recruitment script in a first year dental school class. The purpose, design, and potential risks of the study were explained to the perspective raters. The first 16 non-orthodontic professional volunteers were given an Only Minimal Risk Consent Information and HIPAA Form, and given the opportunity to ask questions. The raters were informed that they would be seeing cropped and deidentified photos from existing patient charts. Once all questions were answered, the non-orthodontic professional raters agreed to participate in the survey, and the Consent Information Form was signed. The 16 West Virginia University School of Dentistry orthodontic faculty member/residents were 
recruited in a similar manner: a recruitment script was used, purpose, design, and potential risks were explained, and Only Minimal Risk Consent Information and HIPAA Form was signed.

\section{OBTAINING REPOSE AND SMILING PROFILE PHOTOGRAPHS}

The pre-treatment and post-treatment repose and smiling profile photos of the 39 subjects (20 non-extraction and 19 four premolar extraction) were obtained from Dolphin Imaging Software Version 11.9 (Dolphin Imaging \& Management Solutions, Chatsworth, CA, USA). Photos were corrected for natural head position prior to export into Microsoft PowerPoint ${ }^{\mathrm{TM}}$. Once in PowerPoint, the photos were cropped to depict the nose, chin, and mouth. For each subject, two PowerPoint slides were created that depicted pre-treatment and post-treatment profile photos in repose on one slide, and pre-treatment and post-treatment photos in smiling on a second slide. This was done for all 39 subjects.

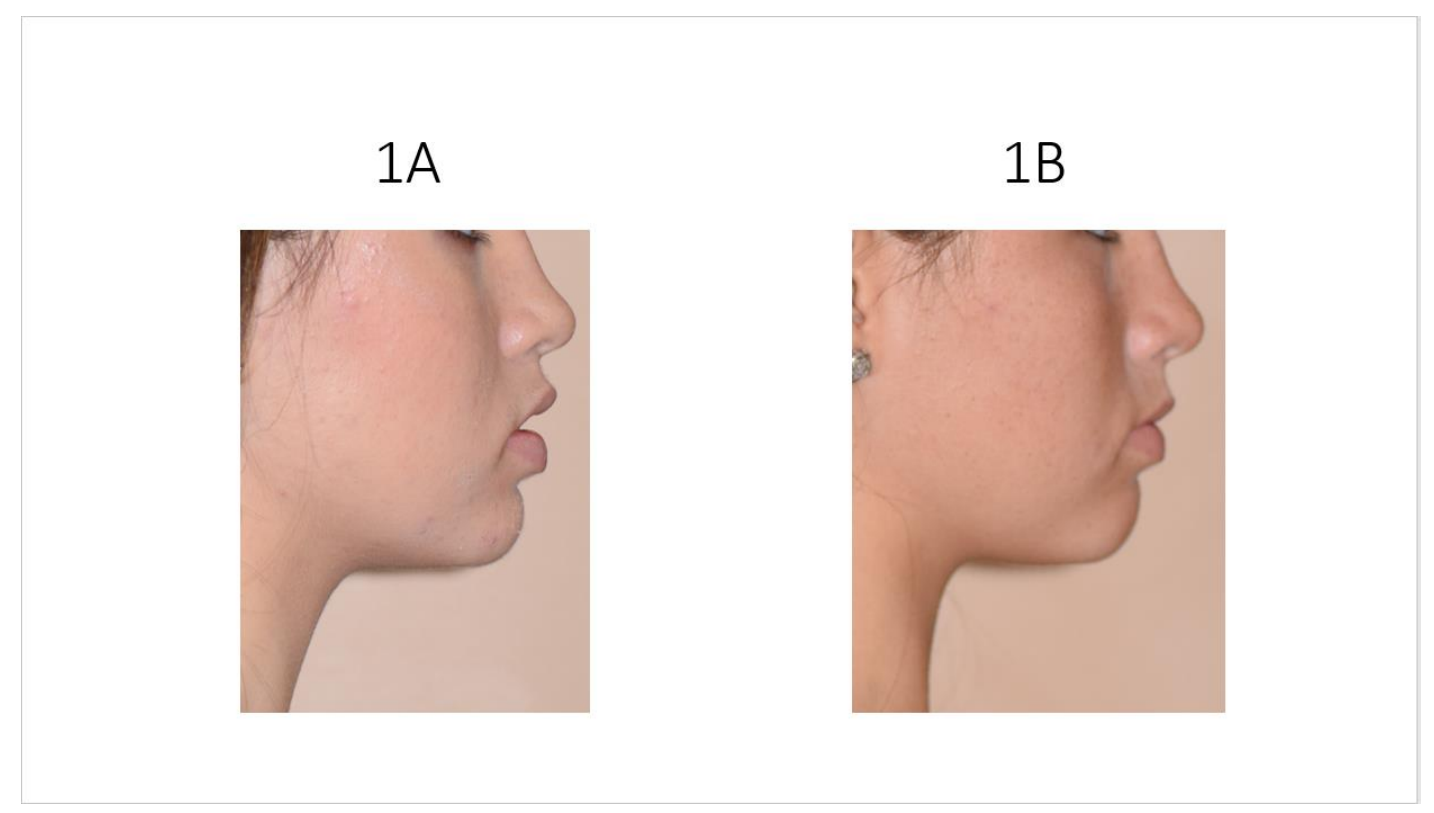

Figure 6: PowerPoint Slide of a subject in repose 


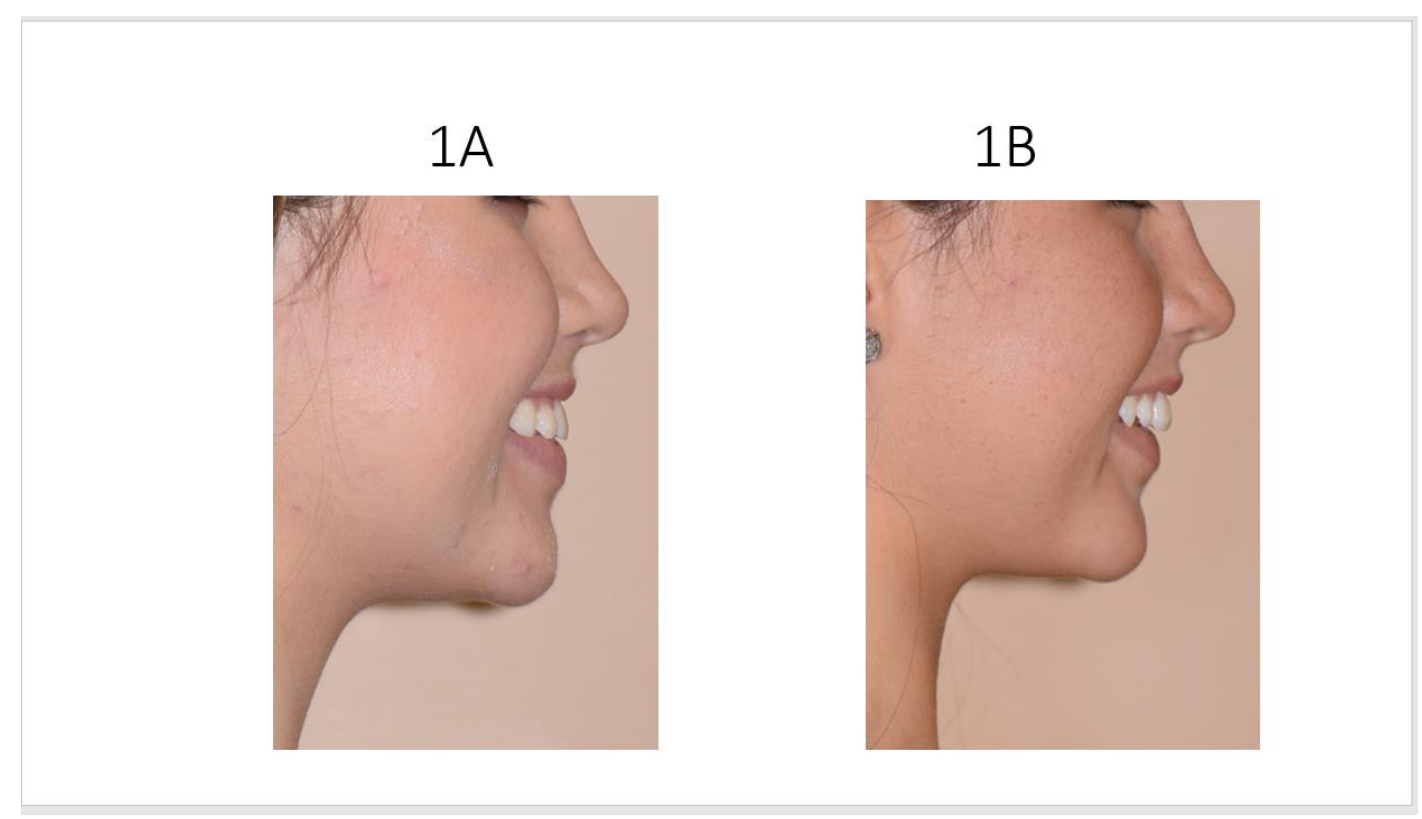

Figure 7: PowerPoint slide of a subject in smiling

A PowerPoint presentation was generated that included the 20 non-extraction subjects' repose pre-treatment and post-treatment photos, the 20 non-extraction patients' smiling pre-treatment and post-treatment photos, the 19 four premolar extraction patients' repose pre-treatment and post-treatment photos, and the 19 four premolar extraction patients' smiling pre-treatment and post-treatment photos. All of the repose slides were placed into the PowerPoint presentation, followed by the smiling slides. Each slide was randomly assigned to have the pre-treatment photo displayed on the left or the right, so as to not allow the rater to assume that the pretreatment photo was always on the left side of the slide. Additionally, the non-extraction and four premolar extraction slides were randomly assorted within the repose portion of the presentation, as well as within the smiling portion of the presentation. 


\section{RATING THE PHOTOGRAPHS}

The raters included 16 laypersons and 16 West Virginia University School of Dentistry orthodontic faculty members/residents. The laypersons viewed the PowerPoint presentation in the Health Science Center, and the orthodontic faculty members/residents viewed the PowerPoint presentation in the WVU Orthodontic Conference Room. Each rater was given a survey which consisted of 2 Visual Analogue Scales per PowerPoint Slide. Each slide was projected for 15 seconds, and the raters were asked to evaluate the attractiveness of the profiles, particularly the area of the mouth, and mark a vertical line along each of the scales to represent where each photo falls on the scale from "not at all attractive" to "very attractive."

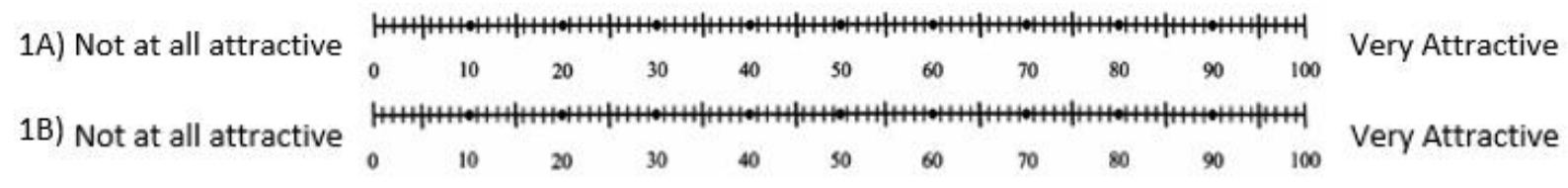

Figure 8: Two visual analogue scales provided for each PowerPoint slide

The raters did this for the 39 slides in repose and then the 39 slides in smiling. After a two week time period passed, 8 of the 16 laypersons and 8 of the 16 West Virginia University School of Dentistry orthodontic faculty members/residents were randomly selected and asked to repeat the same survey in order to produce intra-rater reliability for the study. 


\section{SUPERIMPOSITION OF PRE-TREATMENT AND POST-TREATMENT LATERAL CEPHALOGRAMS}

Pre-treatment and post-treatment lateral cephalogram DICOM files for the 39 subjects were obtained from MiPACS Dental Enterprise Viewer. The DICOM images were exported to Dolphin Imaging Software and saved. Each lateral cephalogram was then corrected to adjusted natural head position and digitized using multiple skeletal, dental, and soft tissue landmarks, so that a 1:1 image could be generated.

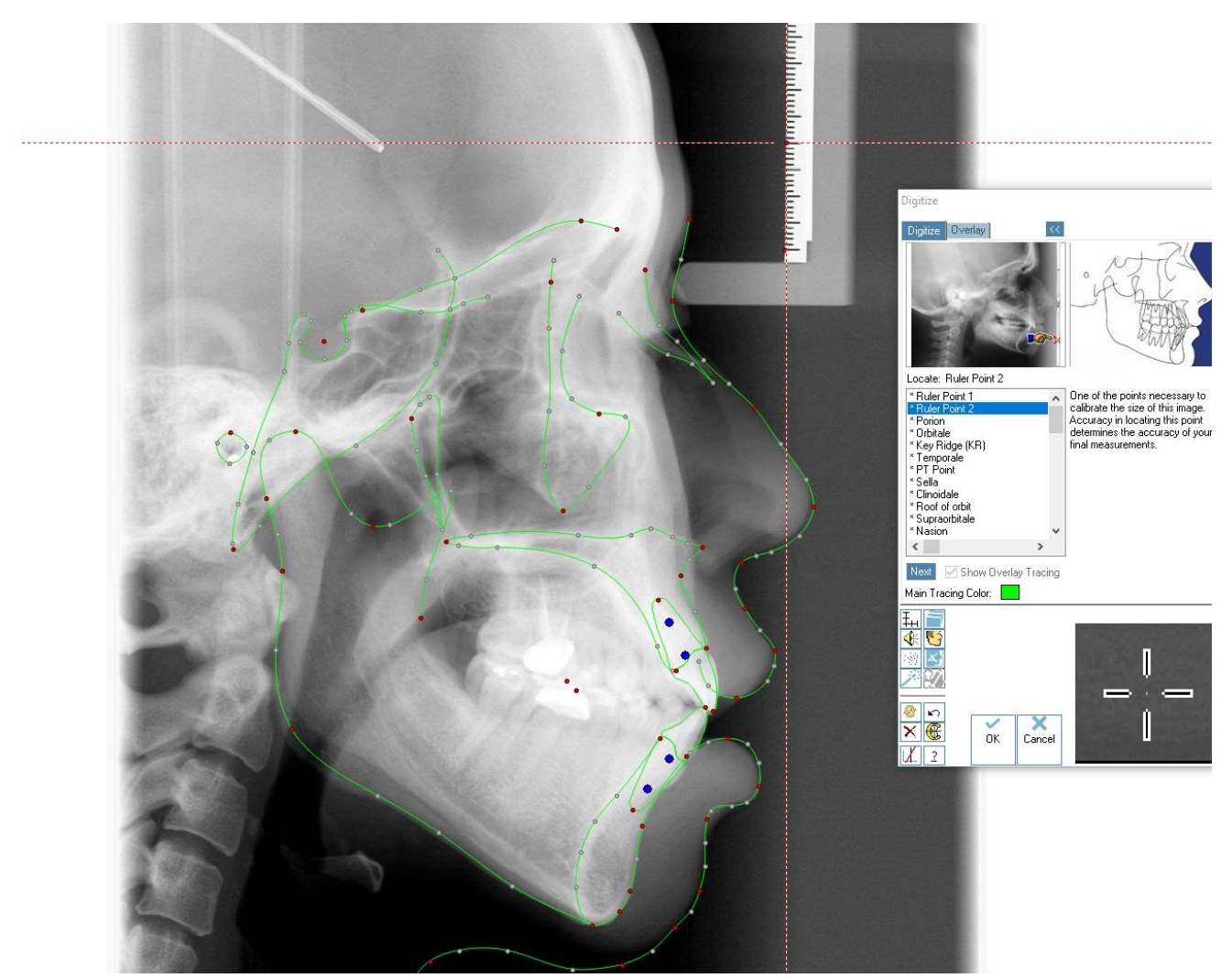

Figure 9: Digitization of lateral cephalogram in Dolphin Imaging

Once the pre-treatment and post-treatment lateral cephalograms were digitized in Dolphin Imaging, a superimposition of the two images was created using cranial base reference structures. The objective was to obtain the closest coincidence of the following structures: 
anterior wall of sella turcica, cribiform plate, trabecular pattern of the superior portion of the ethmoid bone, medial border of the orbital roof, anterior walls of the median cranial fossa. ${ }^{49}$ Rationale for superimposition on the cranial base is so that the operator can assess the total changes of movement in the maxilla, as well as displacement of maxillary teeth due to jaw growth.

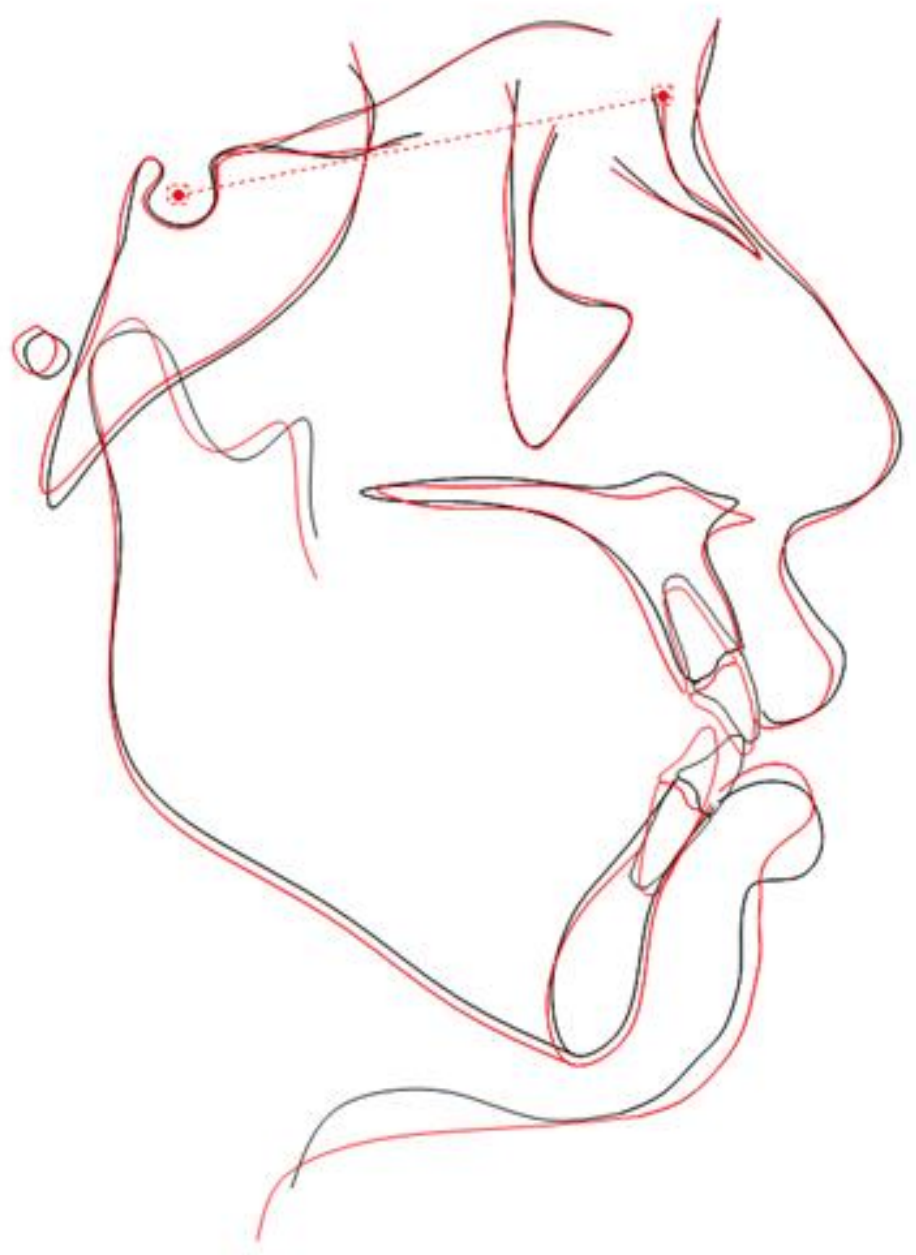

Figure 10: Superimposition of pre-treatment and post-treatment lateral cephalograms 


\section{MEASURING AP CHANGE OF UPPER INCISORS}

To determine the effect of growth, the change in the position of A point of the maxilla must be subtracted from the total change of the upper incisor position found in the cranial base superimposition. This methodology allows a quantitative assessment of the skeletal and dental changes in the maxilla that contribute to the change in the anteroposterior position of the upper incisor. Using the Measurement feature within Dolphin Imaging, a true vertical line was generated upon the adjusted natural head position superimposition through the tangent point of the anterior wall of sella turcica. Then, perpendicular ruler lines were created from the vertical line to the pre-treatment and post-treatment A points and midpoint of the facial axis of the clinical upper incisors crown (FA point). The difference between the A points and the FA points was tabulated. Calculating the difference between these values results in the AP change of the upper incisor position, which could be a positive value, negative value, or 0 ; this indicates whether the incisor moved anteriorly, posteriorly, or did not move.

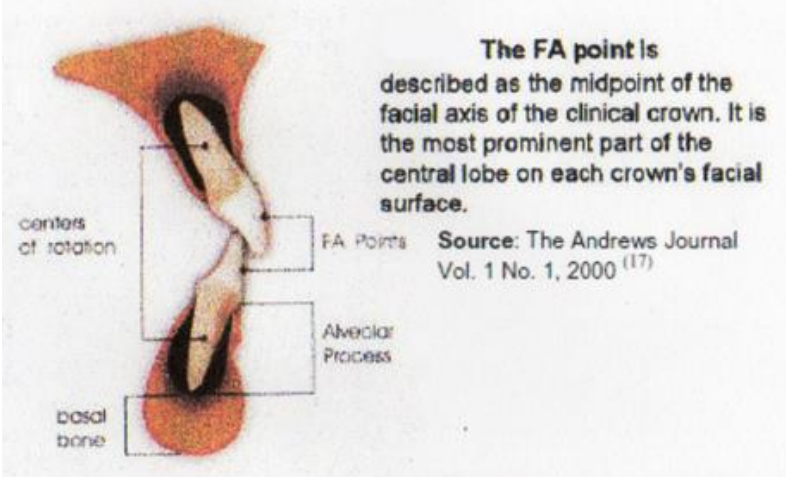

Figure 11: Facial axis of upper incisor (FA point). Taken from The Andrews Journal Vol. 1, No. $1,2000$. 


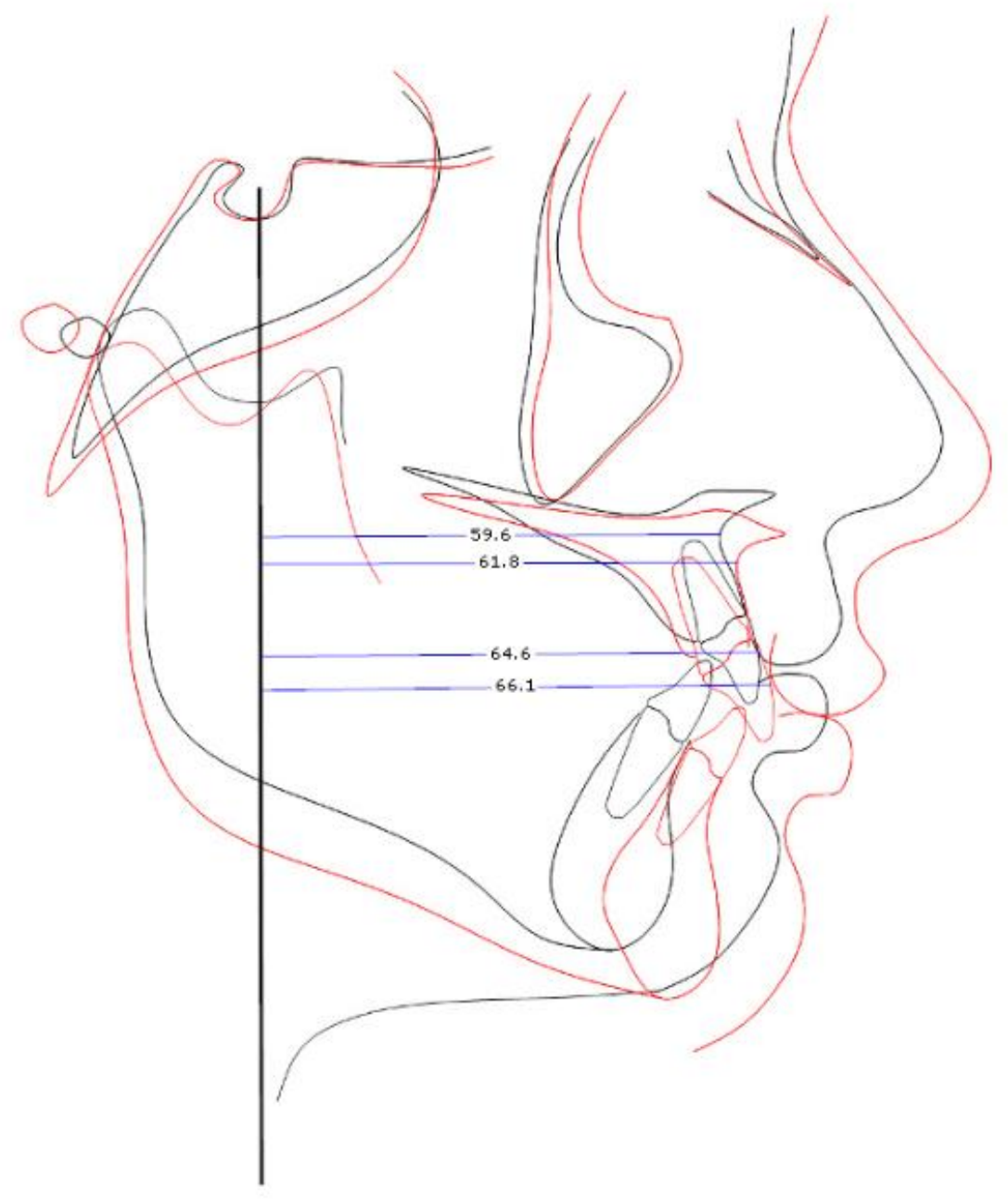

Figure 12: Measuring points and lines used for calculating AP change of upper incisors

\section{RECORDING DATA}

Each of the values on the visual analogue scales was identified from 0-100, and entered into a Microsoft Excel workbook.

The anterior-posterior change of the upper incisors from pre-treatment to post-treatment was obtained from the superimposition of the lateral cephalograms using the cranial base as a 
registration, as previously described. The measurements were entered into a Microsoft Excel workbook.

\section{STATISTICAL ANALYSIS}

All statistical tests were conducted using SAS (version 9.4, 2013, SAS Institute Inc., Cary, NC). Descriptive analyses were performed for basic information of raters and subjects. As the difference in individual facial attractiveness was assumed, the post-treatment and pre-treatment difference of attractiveness ranking scores for each subject and then all subjects was compared using paired t test. To examine the effects of extraction vs. non-extraction, orthodontists vs. laypersons, and retraction level on the facial attractiveness scores, Analysis of Covariance (ANCOVA) was incorporated using post-treatment ranking scores as the dependent variable and pre-treatment attractiveness ranking scores as a covariate. Intra-class correlation coefficient was calculated to assess the reliability of the repeated attractiveness rating scores. All statistical tests were two-sided and p-value of less than 0.05 was considered statistically significant. 


\section{CHAPTER 4: RESULTS}

\section{RELIABILITY RESULTS}

The intra-class correlation coefficient $(\mathrm{ICC})=0.793$, with $95 \% \mathrm{CI}(0.776,0.809)$ indicates there is strong evidence for the repeatability of the rating scores at the two time points.

\section{DATA COLLECTION}

Table 1 summarizes the characteristics of the study participants. The sample of 32 total raters consisted of 16 orthodontists and 16 laypersons. 14 of the $32(43.8 \%)$ raters were male, and the remaining 18 raters were female $(56.2 \%)$. The subjects in the sample consisted of pre and posttreatment photographs of 20 subjects treated with non-extraction therapy and 19 subjects treated with four premolar therapy.

Table 1: Participants' characteristics

\begin{tabular}{|c|c|}
\hline $\begin{array}{l}\text { Rater characteristics } \\
\qquad(\mathrm{n}=32)\end{array}$ & $\mathrm{n}(\%)$ \\
\hline \multicolumn{2}{|l|}{ Sex: } \\
\hline Male & $14(43.8)$ \\
\hline Female & $18(56.2)$ \\
\hline \multicolumn{2}{|l|}{ Group: } \\
\hline Orthodontic Professionals & $16(50.0)$ \\
\hline Laypersons & $16(50.0)$ \\
\hline \multicolumn{2}{|l|}{$\begin{array}{c}\text { Subject characteristics } \\
(n=39)\end{array}$} \\
\hline \multicolumn{2}{|l|}{ Extraction: } \\
\hline Extraction & $19(48.7)$ \\
\hline Non-extraction & $20(51.3)$ \\
\hline
\end{tabular}




\section{AMOUNT OF INCISOR RETRACTION}

Table 2 summarizes the average difference in incisor retraction between the extraction and nonextraction groups. Among the 19 extraction subjects, the average amount of incisor retraction was $-2.5 \pm 1.7 \mathrm{~mm}(\mathrm{SD}=1.7)$. Among the 20 non-extraction subjects, the average amount of incisor retraction was $-0.1 \pm 1.0 \mathrm{~mm}(\mathrm{SD}=1.0)$. The average amount of incisor retraction among all of the 39 subjects was $-1.3 \pm 1.8 \mathrm{~mm}$. The subjects with extraction therapy have a significantly greater amount of incisor retraction than non-extraction subjects $(-2.5 \mathrm{~mm}$ vs. $-0.1 \mathrm{~mm}$, $\mathrm{p}<0.0001)$.

Table 2: Subjects' amount of retraction by extraction status $(\mathrm{n}=39)$

\begin{tabular}{|l|c|c|c|}
\hline \multirow{2}{*}{\multicolumn{1}{c|}{ Extraction }} & \multicolumn{2}{|c|}{ Retraction } & \multirow{2}{*}{} \\
\cline { 2 - 3 } & Mean $(\mathrm{mm})$ & $\mathrm{SD}$ & \multirow{2}{*}{$\mathrm{P}^{\mathrm{a}}$} \\
\hline Extraction $(\mathrm{n}=19)$ & -2.5 & 1.7 & $<0.0001^{*} * *$ \\
\hline Non-extraction $(\mathrm{n}=20)$ & -0.1 & 1.0 & \\
\hline & & & \\
\hline Entire sample $(\mathrm{n}=39)$ & -1.3 & 1.8 & \\
\hline
\end{tabular}

${ }^{\mathrm{a}} \mathrm{p}$-value of two sample t test $*<0.05, * *<0.01, * * *<0.001$

\section{DIFFERENCE IN PRE AND POST-TREATMENT FACIAL ATTRACTIVENESS IN REPOSE AND SMILING COMBINED}

The mean differences between pre-treatment and post-treatment judged facial attractiveness in repose and smiling combined for each subject are summarized in Table 3. A positive mean difference indicates that the subject was judged to be more attractive after treatment, while a negative mean difference indicates that the subject was judged to be less attractive after treatment. The mean scores were variable, with large standard deviations. A range of 38.0 was 
tabulated for this data. However, a statistically significant difference between the pre-treatment and post-treatment ranking scores $(\mathrm{p}<0.05)$ was observed in 21 of the 39 subjects. The mean difference for the sample was $2.8 \pm 28.1$.

Table 3: Difference between pre and post-treatment ranking scores of all subjects

\begin{tabular}{|c|c|c|c|c|c|}
\hline \multirow[t]{2}{*}{ Subject } & \multirow{2}{*}{$\begin{array}{l}\text { Retraction } \\
(\mathrm{mm})\end{array}$} & \multirow{2}{*}{$\begin{array}{l}\text { Retraction } \\
\text { level }^{\mathrm{a}}\end{array}$} & \multicolumn{2}{|c|}{ Post - Pre } & \multirow[t]{2}{*}{$\mathrm{P}^{\mathrm{b}}$} \\
\hline & & & MEAN & SD & \\
\hline 1 & 0 & 2 & -2.6 & 20.5 & 0.31 \\
\hline 2 & 1.5 & 3 & 11.7 & 29.1 & $0.002 * *$ \\
\hline 3 & -1.4 & 2 & 8.4 & 33.0 & $0.04 *$ \\
\hline 4 & -0.5 & 2 & 23.9 & 21.1 & $<0.0001 * * *$ \\
\hline 5 & -2.3 & 1 & 6.2 & 31.2 & 0.12 \\
\hline 6 & 0.7 & 3 & 4.0 & 29.1 & 0.27 \\
\hline 7 & -1.2 & 2 & -1.5 & 20.8 & 0.55 \\
\hline 8 & -0.1 & 2 & 12.3 & 21.7 & $<0.0001^{* * * *}$ \\
\hline 9 & -0.5 & 2 & 7.3 & 27.2 & $0.03 *$ \\
\hline 10 & -1.6 & 2 & 9.0 & 27.7 & $0.02^{*}$ \\
\hline 11 & 0.7 & 3 & -0.7 & 24.0 & 0.82 \\
\hline 12 & 0.5 & 3 & 3.2 & 25.3 & 0.32 \\
\hline 13 & 1 & 3 & 0.7 & 20.3 & 0.80 \\
\hline 14 & -0.7 & 2 & -2.9 & 31.9 & 0.47 \\
\hline 15 & -0.4 & 2 & 3.5 & 28.7 & 0.34 \\
\hline 16 & -0.5 & 2 & -7.8 & 23.0 & $0.009^{* *}$ \\
\hline 17 & -0.4 & 2 & 6.9 & 21.1 & $0.01 *$ \\
\hline 18 & 1 & 3 & -3.0 & 30.8 & 0.43 \\
\hline 19 & 1.4 & 3 & 6.3 & 22.1 & $0.03 *$ \\
\hline 20 & 0.7 & 3 & -2.5 & 16.0 & 0.21 \\
\hline 21 & -1.9 & 2 & -6.3 & 23.5 & $0.04 *$ \\
\hline 22 & -1.1 & 2 & 18.3 & 15.7 & $<0.0001 * * *$ \\
\hline 23 & -6.4 & 1 & -12.2 & 33.0 & $0.006^{* *}$ \\
\hline 24 & -2 & 2 & 16.7 & 23.3 & $<0.0001 * * *$ \\
\hline 25 & -5.4 & 1 & -8.2 & 36.8 & 0.08 \\
\hline 26 & -2.9 & 1 & 19.8 & 24.2 & $<0.0001 * * *$ \\
\hline 27 & 0 & 2 & 5.6 & 25.9 & 0.09 \\
\hline 28 & -2.4 & 1 & 2.6 & 32.9 & 0.52 \\
\hline 29 & -0.9 & 2 & 12.1 & 27.0 & $0.0007 * * *$ \\
\hline 30 & -2.3 & 1 & -4.1 & 33.7 & 0.34 \\
\hline 31 & -2.8 & 1 & -14.1 & 34.8 & $0.002 * *$ \\
\hline 32 & -1.8 & 2 & 0.6 & 29.3 & 0.87 \\
\hline 33 & -0.8 & 2 & -13.5 & 26.9 & $<0.0001 * * *$ \\
\hline
\end{tabular}




\begin{tabular}{|l|l|l|r|r|r|}
\hline 34 & -3.8 & 1 & 8.9 & 28.0 & $0.01^{*}$ \\
\hline 35 & -5.1 & 1 & 0.8 & 26.5 & 0.80 \\
\hline 36 & -3.7 & 1 & -8.6 & 19.0 & $0.0006^{* * *}$ \\
\hline 37 & -2.2 & 1 & 8.9 & 31.6 & $0.03^{*}$ \\
\hline 38 & -1 & 2 & 4.7 & 27.3 & 0.17 \\
\hline 39 & -1.8 & 2 & -5.7 & 22.3 & $0.04^{*}$ \\
\hline All subjects & & & 2.8 & 28.1 & $<0.0001^{* * *}$ \\
\hline
\end{tabular}

${ }^{a}$ Retraction level: $1=<-2 \mathrm{~mm}, 2=-2-0 \mathrm{~mm}, 3=>0 \mathrm{~mm}$.

${ }^{\mathrm{b}} \mathrm{p}$-value for paired t test. $*<0.05, * *<0.01, * * *<0.001$

DIFFERENCE BETWEEN PRE AND POST-TREATMENT FACIAL ATTRACTIVENESS REPOSE AND SMILING INDEPENDENTLY

Table 4 summarizes the mean differences between pre-treatment and post-treatment judged facial attractiveness in repose and smiling independently. For the repose data, a statistically significant difference between the pre-treatment and post-treatment ranking scores $(\mathrm{p}<0.05)$ was observed in 28 of the 39 subjects. 11 of the 39 subjects $(28.2 \%)$ had a positive mean difference in repose. The mean difference for the repose data was $-5.7 \pm 27.6$ post-treatment. For the smiling data, a statistically significant difference between the pre-treatment and posttreatment ranking scores $(\mathrm{p}<0.05)$ was also observed in 28 of the 39 subjects. However, the significant difference was not always observed in the same 28 subjects that were significant in repose. 30 of the 39 subjects $(76.9 \%)$ had a positive mean difference in smiling. The overall mean difference for the smiling data was $11.3 \pm 26.0$ post-treatment. Figure 13 displays the mean differences for all of the subjects in repose and smiling.

Table 4: Difference between pre and post-treatment ranking scores for repose and smiling pictures by subject

\begin{tabular}{|c|c|c|c|c|c|c|}
\hline \multirow[t]{2}{*}{ Subject } & \multicolumn{2}{|c|}{$\begin{array}{c}\text { Post - Pre } \\
(\text { repose })\end{array}$} & & \multicolumn{2}{|c|}{$\begin{array}{c}\text { Post }- \text { Pre } \\
(\text { smiling })\end{array}$} & \multirow[b]{2}{*}{$\mathrm{P}^{\mathrm{b}}$} \\
\hline & MEAN & SD & $\mathrm{P}^{\mathrm{b}}$ & MEAN & $\mathrm{SD}$ & \\
\hline
\end{tabular}




\begin{tabular}{|c|c|c|c|c|c|c|}
\hline 1 & -2.3 & 24.6 & 0.61 & -3.0 & 15.8 & 0.29 \\
\hline 2 & 22.9 & 30.0 & $0.0001 * * *$ & 0.4 & 23.8 & 0.92 \\
\hline 3 & -15.4 & 28.5 & $0.005 * *$ & 32.1 & 15.5 & $<0.0001 * * *$ \\
\hline 4 & 28.1 & 20.1 & $<0.0001 * * *$ & 19.7 & 21.5 & $<0.0001 * * *$ \\
\hline 5 & -14.3 & 29.6 & $0.01^{*}$ & 26.7 & 15.6 & $<0.0001 * * *$ \\
\hline 6 & -8.7 & 25.2 & 0.06 & 16.8 & 27.4 & $0.002^{* *}$ \\
\hline 7 & -0.2 & 18.5 & 0.95 & -2.9 & 23.1 & 0.48 \\
\hline 8 & 8.2 & 20.2 & $0.03 *$ & 16.5 & 22.7 & $0.0003 * * *$ \\
\hline 9 & -2.7 & 27.5 & 0.59 & 17.3 & 23.2 & $0.0002^{* *}$ \\
\hline 10 & 20.0 & 21.0 & $<0.0001 * * *$ & -2.1 & 29.5 & 0.69 \\
\hline 11 & -12.8 & 18.9 & $0.0006^{* * *}$ & 11.4 & 22.6 & $0.008 * *$ \\
\hline 12 & 8.6 & 24.9 & 0.06 & -2.2 & 24.8 & 0.62 \\
\hline 13 & -10.5 & 16.6 & $0.001 * *$ & 11.8 & 17.4 & $0.0006 * * *$ \\
\hline 14 & 8.2 & 29.8 & 0.13 & -14.0 & 30.5 & $0.01 *$ \\
\hline 15 & -9.6 & 25.6 & $0.04 *$ & 16.5 & 25.7 & $0.001 * *$ \\
\hline 16 & -8.1 & 19.6 & $0.03 *$ & -7.4 & 26.2 & 0.12 \\
\hline 17 & -6.6 & 16.5 & $0.03 *$ & 20.5 & 16.0 & $<0.0001 * * *$ \\
\hline 18 & -26.9 & 19.6 & $<0.0001 * * *$ & 20.9 & 19.0 & $<0.0001 * * *$ \\
\hline 19 & -6.3 & 20.2 & 0.09 & 18.8 & 16.1 & $<0.0001 * * *$ \\
\hline 20 & -0.9 & 14.0 & 0.71 & -4.2 & 17.9 & 0.20 \\
\hline 21 & -19.0 & 18.5 & $<0.0001 * * *$ & 6.5 & 21.1 & 0.09 \\
\hline 22 & 18.2 & 14.1 & $<0.0001 * * *$ & 18.5 & 17.4 & $<0.0001 * * *$ \\
\hline 23 & -35.3 & 22.6 & $<0.0001 * * *$ & 11.0 & 26.9 & $0.03^{*}$ \\
\hline 24 & 18.9 & 24.8 & $0.0001 * * *$ & 14.5 & 21.8 & $0.0007 * * *$ \\
\hline 25 & -35.2 & 21.6 & $<0.0001 * * *$ & 18.8 & 28.0 & $0.0006 * * *$ \\
\hline 26 & 24.0 & 17.9 & $<0.0001 * * *$ & 15.5 & 28.9 & $0.005^{* *}$ \\
\hline 27 & -11.6 & 18.5 & $0.001 * *$ & 22.8 & 20.1 & $<0.0001 * * *$ \\
\hline 28 & -18.8 & 24.8 & $0.0002 * * *$ & 24.0 & 25.4 & $<0.0001 * * *$ \\
\hline 29 & 2.4 & 27.5 & 0.62 & 21.8 & 23.1 & $<0.0001 * * *$ \\
\hline 30 & -29.3 & 18.6 & $<0.0001 * * *$ & 21.2 & 25.3 & $<0.0001 * * *$ \\
\hline 31 & -39.1 & 21.1 & $<0.0001 * * *$ & 20.9 & 26.8 & $0.03^{*}$ \\
\hline 32 & -14.6 & 22.7 & $0.001 * *$ & 15.8 & 27.4 & $0.003 * *$ \\
\hline 33 & -13.2 & 23.4 & $0.003 * *$ & -13.8 & 28.5 & $0.01^{*}$ \\
\hline 34 & -10.5 & 20.4 & $0.006^{* *}$ & 28.3 & 20.0 & $<0.0001 * * *$ \\
\hline 35 & -13.6 & 20.8 & $0.0008 * * *$ & 15.3 & 23.9 & $0.001 * *$ \\
\hline 36 & -0.3 & 21.1 & 0.94 & -17.0 & 12.1 & $<0.0001 * * *$ \\
\hline 37 & 10.3 & 29.5 & 0.06 & 7.6 & 34.0 & 0.22 \\
\hline 38 & -11.3 & 20.2 & $0.004 * *$ & 20.8 & 24.1 & $0.0009 * * *$ \\
\hline 39 & -14.9 & 20.0 & $0.0002 * * *$ & 3.6 & 18.5 & 0.28 \\
\hline All subjects & -5.7 & 27.6 & $<0.0001 * * *$ & 11.3 & 26.0 & $<0.0001 * * *$ \\
\hline
\end{tabular}

${ }^{\mathrm{b}} \mathrm{p}$-value for paired t test. $*<0.05, * *<0.01, * * *<0.001$ 
Figure 13: Means of difference for Repose and Smiling

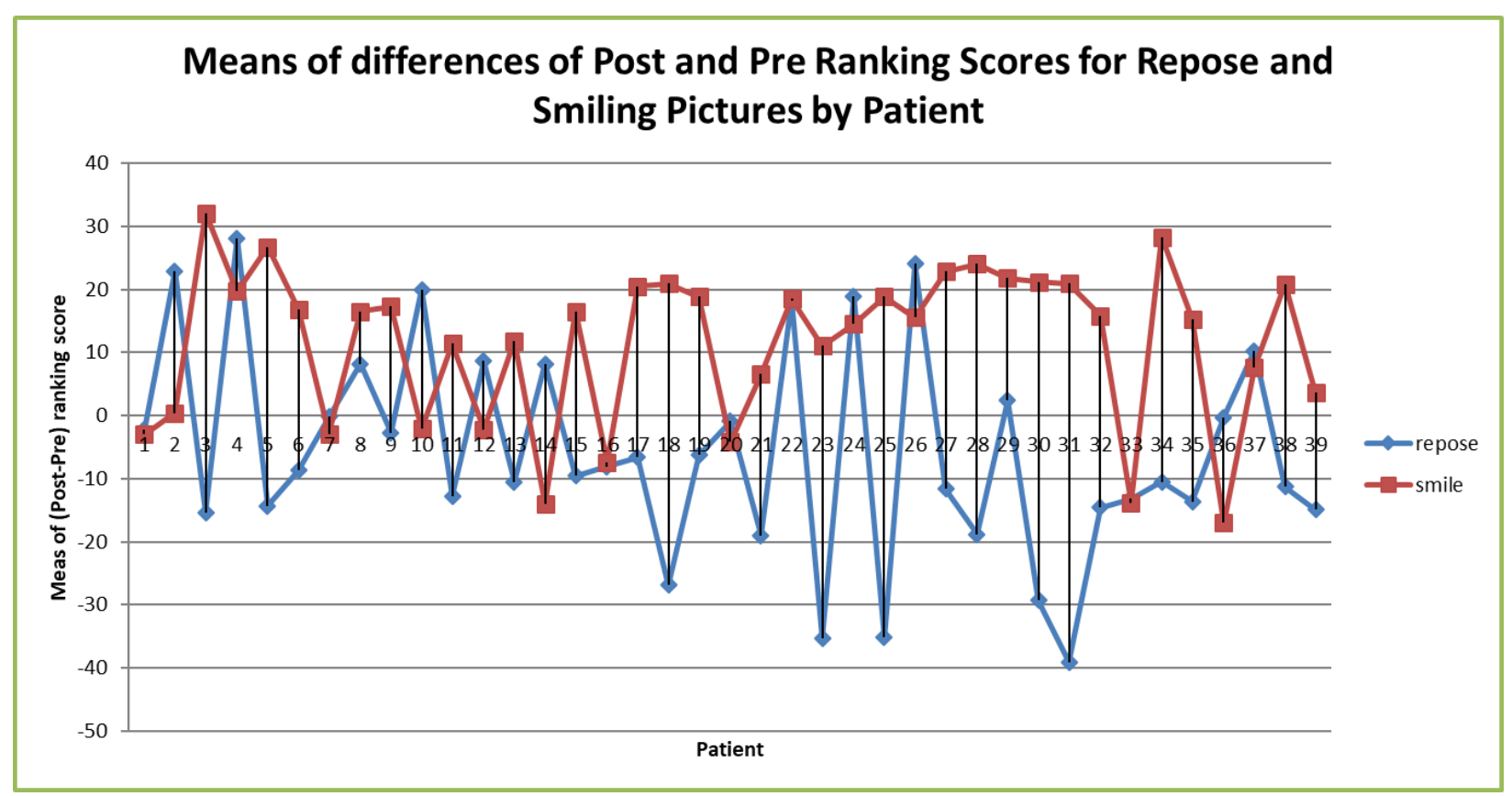

\section{REPOSE DATA}

For the repose data, Table 5 summarizes any association between judged facial attractiveness and 1) extraction status (four premolar extraction vs. non-extraction), 2) group (orthodontic professional vs. layperson), 3) retraction level, and 4) all variables combined. No statistically significant difference in attractiveness ranking scores between extraction and non-extraction subjects $(\mathrm{p}>0.05)$ was observed. A significant difference in attractiveness ranking scores between orthodontic professionals and laypersons was observed. Orthodontists gave higher attractiveness ranking scores than laypersons (41.5 vs. $36.2, \mathrm{p}<0.05)$ as shown in Table 6 and Figure 15. Additionally, a significant difference in attractiveness ranking scores among the different levels of retraction was found. Subjects in the $<-2 \mathrm{~mm}$ retraction group were judged to be more attractive than subjects who are in the $-2-0 \mathrm{~mm}$ retraction group (42.0 vs. 35.3, 
$\mathrm{p}<0.05)$. Subjects in the $>0 \mathrm{~mm}$ retraction group are more attractive than subjects in the $-2-0$ retraction group (43.4 vs. 35.3 , $\mathrm{p}<0.05)$. There was no statistically significant difference between the $<-2 \mathrm{~mm}$ and $>2 \mathrm{~mm}$ retraction groups $(\mathrm{p}>0.05)$. Figure 14 displays this relationship. Model 4 depicted in Table 5 also confirms the findings: orthodontic professions vs. layperson and the different levels of retraction remain significant; extraction vs. non-extraction therapy is not significant.

Table 5: ANCOVA analysis for association between facial attractiveness and extraction status (model 1), group (model 2), retraction level (model 3), all variables (model 4) adjusted for preattractiveness ranking score for repose data

\begin{tabular}{|c|c|c|c|}
\hline Model & $\mathrm{DF}^{\mathrm{a}}$ & $\mathrm{F}^{\mathrm{b}}$ & $\mathrm{P}^{\mathrm{c}}$ \\
\hline \multicolumn{4}{|l|}{ Model 1} \\
\hline Pre-attractiveness & 1 & 72.1 & $<0.0001 * * *$ \\
\hline Extract & 1 & 0.6 & 0.44 \\
\hline \multicolumn{4}{|l|}{ Model 2} \\
\hline Pre-attractiveness & 1 & 84.3 & $<0.0001 * * *$ \\
\hline Group & 1 & 18.2 & $<0.0001 * * *$ \\
\hline \multicolumn{4}{|l|}{ Model 3} \\
\hline Pre-attractiveness & 1 & 82.0 & $<0.0001 * * *$ \\
\hline Retraction & 2 & 17.8 & $<0.0001 * * *$ \\
\hline \multicolumn{4}{|l|}{ Model 4} \\
\hline Pre-attractiveness & 1 & 78.1 & $<0.0001 * * *$ \\
\hline Extract & 1 & 0.8 & 0.38 \\
\hline Group & & 18.7 & $<0.0001 * * *$ \\
\hline Retraction & & 18.2 & $<0.0001 * * *$ \\
\hline
\end{tabular}

${ }^{\text {a }} \mathrm{DF}=$ degree of freedom

${ }^{\mathrm{b}} \mathrm{F}=\mathrm{F}$-value from F-test (ANCOVA analysis)

${ }^{\mathrm{c}} \mathrm{p}$-value for ANCOVA analysis using post attractiveness ranking score as dependent variable and pre-attractiveness ranking score as a covariate. $*<0.05, * *<0.01, * * *<0.001$ 
Table 6: Least Square means comparison for retraction level and group for repose data

\begin{tabular}{|l|l|l|l|l|l|}
\hline \multicolumn{5}{|c|}{ Retraction level } \\
\hline LS means & Std err & LS means & Std err & LS means & Std err \\
\hline $42.0^{\mathrm{a}}$ & 1.2 & $35.3^{\text {ab }}$ & 0.9 & $43.4^{\mathrm{b}}$ & 1.4 \\
\hline \multicolumn{7}{|c|}{ Group } \\
\hline \multicolumn{7}{|c|}{ Orthodontists } & LS means & Laypersons \\
\hline LS means & Std err & $36.2^{\mathrm{c}}$ & 0.9 \\
\hline $41.5^{\mathrm{c}}$ & 0.9 & Std err & \\
\hline
\end{tabular}

${ }^{\mathrm{a}}$ significant difference $(\mathrm{p}<0.05)$ between retraction level $1(<-2 \mathrm{~mm})$ and $2(-2 \mathrm{~mm}-0 \mathrm{~mm})$.

${ }^{\mathrm{b}}$ significant difference $(\mathrm{p}<0.05)$ between retraction level $2(-2 \mathrm{~mm}-0 \mathrm{~mm})$ and $3(>0 \mathrm{~mm})$.

${ }^{\mathrm{c}}$ significant difference $(\mathrm{p}<0.05)$ between orthodontists and laypersons

Figure 14: LS Means for Retraction Level

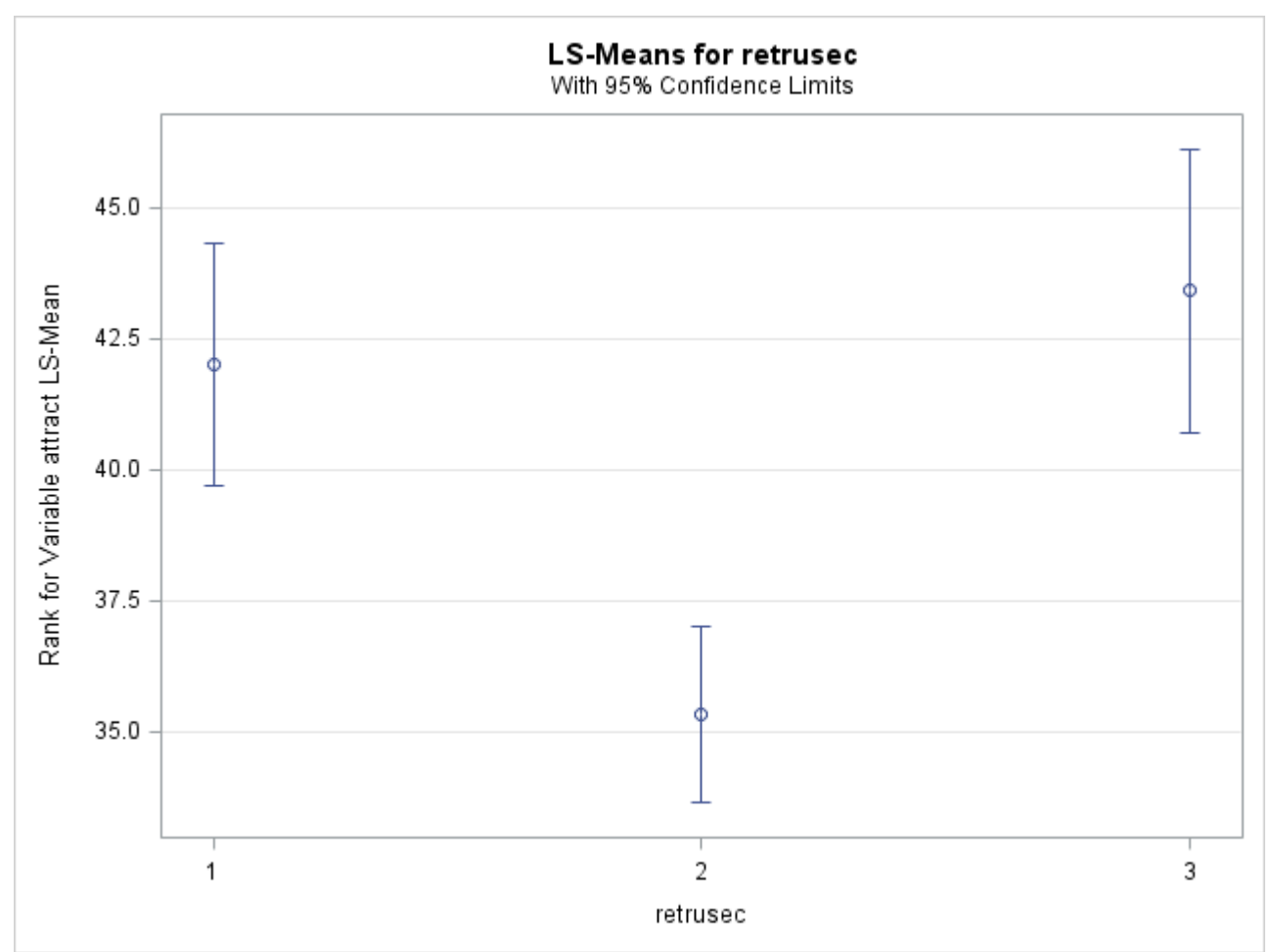


Figure 15: LS Means for Orthodontic Professionals and Laypersons

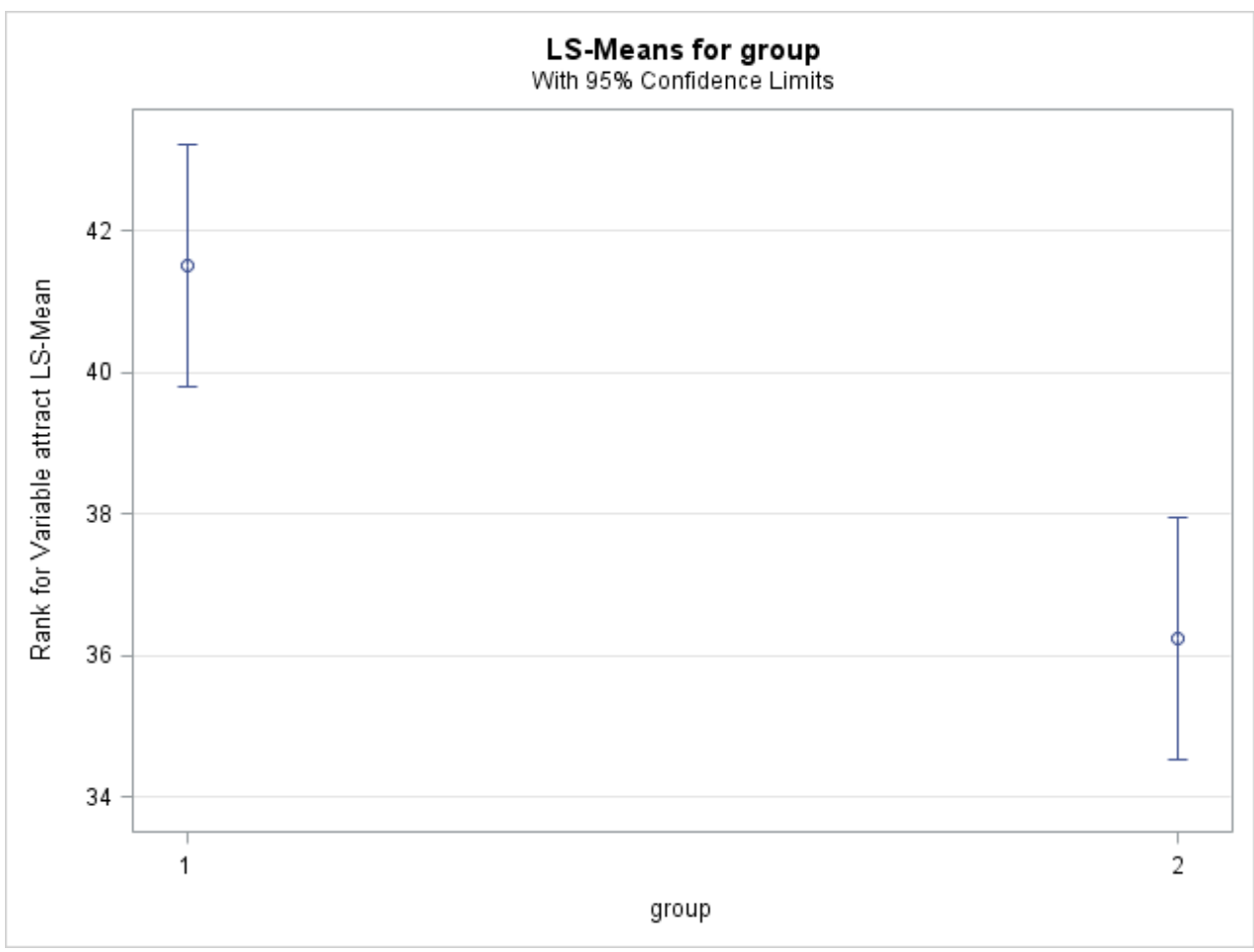




\section{SMILING DATA}

Table 7 summarizes the analysis between judged facial attractiveness and 1) extraction status (four premolar extraction vs. non-extraction), 2) group (orthodontic professional vs. layperson), 3) retraction level, and 4) all variables combined. No significant differences were observed for any of the variables, nor when combined.

Table 7: ANCOVA analysis for association between facial attractiveness and extraction status (model 1), group (model 2), retraction level (model 3), all variables (model 4) adjusted for preattractiveness ranking score for smiling data

\begin{tabular}{|l|l|l|l|}
\hline Model & $\mathrm{DF}^{\mathrm{a}}$ & $\mathrm{F}^{\mathrm{b}}$ & $\mathrm{P}^{\mathrm{c}}$ \\
\hline Model 1 & \multicolumn{2}{l|}{} \\
\hline Pre-attractiveness & 1 & 116.0 & $<0.0001^{* * *}$ \\
\hline Extract & 1 & 1.1 & 0.30 \\
\hline Model 2 & \multicolumn{2}{l|}{} \\
\hline Pre-attractiveness & 1 & 122.2 & $<0.0001^{* * *}$ \\
\hline Group & 1 & 0.2 & 0.68 \\
\hline Model 3 & \multicolumn{1}{l|}{} \\
\hline Pre-attractiveness & 1 & 113.4 & $<0.0001^{* * *}$ \\
\hline Retraction & 2 & 2.5 & 0.08 \\
\hline Model 4 & \multicolumn{1}{|l|}{} \\
\hline Pre-attractiveness & 1 & 111.1 & $<0.0001^{* * *}$ \\
\hline Extract & 1 & 0.3 & 0.59 \\
\hline Group & 1 & 0.2 & 0.67 \\
\hline Retraction & 2 & 2.1 & 0.12 \\
\hline
\end{tabular}

${ }^{\mathrm{a}} \mathrm{DF}=$ degree of freedom

${ }^{b} \mathrm{~F}=\mathrm{F}$-value from F-test (ANCOVA analysis)

${ }^{c} \mathrm{p}$-value for ANCOVA analysis using post attractiveness ranking score as dependent variable and pre-attractiveness ranking score as a covariate. $*<0.05, * *<0.01, * * *<0.001$ 


\section{CHAPTER 5: DISCUSSION}

\section{EFFECTS OF EXTRACTION TREATMENT OR INCISOR RETRACTION ON FACIAL ATTRACTIVENESS}

No statistically significant difference in attractiveness ranking scores between extraction and non-extraction subjects $(\mathrm{p}>0.05)$ was observed in either smiling or repose. Thus, the current data set illustrates that extraction therapy is not harmful to the repose profile or the smiling profile. One of the limitations of this study is that the original position of the upper incisor was not determined pre-treatment. It is therefore difficult to assess whether initiating non-extraction therapy or four premolar extraction therapy brought the position of the upper incisors to a more or less harmonious position within the face after treatment. This judgment could be made using traditionally accepted cephalometric norms. As previously mentioned, many authors claim that extraction therapy "dishes in the face," and harms the profile. However, with extraction therapy, it is possible to have the upper incisor remain in the same AP position post-treatment. This is dependent on pre-treatment crowding and careful mechanics. Further analysis with known pretreatment and post-treatment AP position of the upper incisors would lead to the elucidation of more information. Among the post-treatment profiles that were judged to be less attractive, one could identify if there was a statistically significant position or threshold that harmed the profile. This position could exist in both the non-extraction and four premolar extraction groups. A statement could then be made on the relevance of the post-treatment AP position of the upper incisor.

\section{RETRACTION}

In repose, a significant difference in attractiveness ranking scores among the different levels of retraction was found. Subjects in the $<-2 \mathrm{~mm}$ retraction group were judged to be more attractive 
than subjects who are in the $-2-0 \mathrm{~mm}$ retraction group (42.0 vs. $35.3, \mathrm{p}<0.05)$. Subjects in the $>0 \mathrm{~mm}$ retraction group were more attractive than that -2 - $0 \mathrm{~mm}$ retraction group (35.3 vs. 43.4 , $\mathrm{p}<0.05)$. Thus, greater retraction of the incisors was found to make the repose profile more attractive. 9 of the 10 subjects with $<-2 \mathrm{~mm}$ of retraction were from the four premolar extraction group. Therefore, four premolar extraction made the profile more attractive in repose, whenever the incisors were retracted more than $2 \mathrm{~mm}$. As previously mentioned, the study by Johnston concluded that the esthetic benefit of treatment was a combination of being either non-extraction or four premolar extraction, and the initial protrusion of the profile. ${ }^{50}$ The patients in the study were similar at the outset of treatment. However, after treatment, the extraction therapy patients had profiles that were $1.8 \mathrm{~mm}$ "flatter" on average. They deemed that extraction therapy had an esthetic benefit that was proportional to the patient's pre-treatment lip procumbency in relation to Rickett's E-plane. Patients that were more than 2-3 mm behind the plane pre-treatment were seen as having a poor esthetic result if they underwent extraction therapy. They further claimed that non-extraction therapy had little effect on facial esthetics, regardless of initial profile protrusion.

Important to note is that upper incisor retraction does not have a 1:1 ratio of retraction of the upper lip. A 3:1 ratio of incisor retraction to upper lip retraction is more of a shared opinion among orthodontic providers. Consequently, similarities can be drawn between the present study and the study by Johnston, but further studies may expound more connections.

Subjects in the $>0 \mathrm{~mm}$ retraction group were also found to be more attractive than that $-2-0 \mathrm{~mm}$ retraction group. There were 8 subjects in this group; all were non-extraction. The most anterior the upper incisors moved post-treatment on a subject was $1.5 \mathrm{~mm}$. It is possible the raters were looking for a greater change, in a more procumbent direction in order to award a higher 
attractiveness rating. The results are similar to the previously mentioned study by Foster, in which they found fuller lips to be most attractive. ${ }^{51}$

No significant difference was identified among any of the variables in the smiling data. Known pre-treatment and post-treatment AP position of the upper incisors in future studies could lead to the elucidation of a measurement at which if extraction therapy is an option, it would become the preferable treatment option.

\section{PROFESSIONAL VERSUS LAYPERSON ON JUDGED FACIAL ATTRACTIVENESS}

The present study was designed to mimic the routine social judgment made by orthodontic professionals and laypersons on subjects receiving non-extraction and four premolar extraction orthodontic therapy in repose and smiling. The repose and smiling images were presented to the raters, and they were asked to evaluate the attractiveness of the profiles, particularly the area of the mouth, using a Visual Analogue Scale. In repose, a significant difference in attractiveness ranking scores $(\mathrm{p}<0.0001)$ between orthodontic professionals and laypersons was observed. Orthodontists gave higher attractiveness ranking scores than laypersons in repose. This group was more sensitive to the treatment changes, which is rational, as orthodontic training revolves around striving for optimal facial esthetics, with the enhancement of dentofacial characteristics. Laypersons may have been more critical of the repose profile due to other features of the face, not necessarily due to the attractiveness of the mouth. However, in smiling, no significant difference in attractiveness ranking scores between orthodontic professionals and laypersons was observed. In a study by Lauria et al., laypersons criticized smile esthetics more than a cohort of maxillofacial surgeons did. The authors justified their results by the potential influence of dental crowding in the perception of laypersons. ${ }^{52}$ In attempt to eliminate this factor in the present 
study, one of the exclusion criteria for the subjects was that the subjects could not have severely malposed incisors. This exclusion may be reasoning for why no difference in attractiveness ranking scores between orthodontic professionals and laypersons was observed in smiling. Previous studies have provided conflicting results as to whether orthodontists are more sensitive than laypersons in their judgement of facial attractiveness. ${ }^{53}$ The present study contributes to this confusion, as there was a significant difference between orthodontic professionals and laypersons in repose, but not smiling. Minimally, orthodontists should continue to focus on function, periodontal health, stability, and facial esthetics.

\section{POST-TREATMENT DIFFERENCE IN JUDGED FACIAL ATTRACTIVENESS}

When evaluating the repose post-treatment difference in judged facial attractiveness, a statistically significant difference was observed between the pre-treatment and post-treatment ranking scores $(\mathrm{p}<0.05)$ in 28 of the 39 subjects. The mean difference for the repose data was $-5.7 \pm 27.6$ post-treatment. This is simply the average, as for individual subjects the results are different. Although not statistically significant, 11 of the 39 subjects had a positive mean ranking score, meaning that they were judged to be more attractive post-treatment. Thus, undergoing orthodontic treatment improved the repose judged facial attractiveness in less than $1 / 3$ of the subjects $(28.2 \%)$. When evaluating the smiling post-treatment difference in judged facial attractiveness, a statistically significant difference was also observed between the pre-treatment and post-treatment ranking scores $(\mathrm{p}<0.05)$ in 28 of the 39 subjects. The mean difference for the smiling data was $11.3 \pm 26.0$ post treatment. Again, this is simply the average, as for individual subjects the results are different. Important to note is that these were not the same 28 subjects that were significant in the repose grouping. In the smiling photos, 30 of the 39 subjects had a positive ranking score, meaning that they were judged to more attractive post-treatment. 
More subjects were judged to be more attractive post-treatment in smiling than repose (30 versus 11). Thus, the raters found orthodontic treatment to enhance facial attractiveness when the subjects were viewed smiling. The presence of the smile may have influenced the greater perception of attractiveness, and not necessarily a manifestation of what type of therapy (extraction or non-extraction) that was performed. A study of facial esthetics by Yang et al. found a significant difference after adding both sagittal and oblique smiling profiles to a set of records before and after treatment. They suggest integrating oblique and sagittal smiling profiles to the assessment of facial attractiveness when evaluating a patient for facial esthetics. The present study supports this notion, as more of the subjects were found to be more attractive posttreatment when viewed smiling. Although, no significant differences in smiling were found among the different variables investigated in the present study, the smiling profile does seem to be of importance and should be considered when evaluating a patient.

\section{VARIABILITY IN RANKING SCORES AMONG JUDGES ON SUBJECTS}

Large standard deviations, as large as 36.8, were tabulated for the means of difference between pre-treatment and post-treatment ranking scores of a subject. For the repose mean pre-treatment and post-treatment treatment ranking scores, the highest standard deviation was 30.0. For smiling, it was 34.0. For a study in which there is a target or goal, a relationship between the standard deviation and the sample size exists. As sample size increases, then the variability is expected to decrease. This is not the case for this data set. The size of the standard deviations in this study are large, because the aim of the aim of the study was to simply observe and record judged facial attractiveness. Each subject did not have a predetermined or known attractiveness score. The standard deviations simply reflect a large amount of variation in the group that is being studied. 


\section{NULL HYPOTHESIS TESTING}

1. ACCEPTED: There is no difference in the judged facial attractiveness between the nonextraction and four premolar extraction groups repose profiles

2. ACCEPTED: There is no difference in the judged facial attractiveness between the nonextraction and four premolar extraction groups smiling profiles

3. PARTIALLY REJECTED: There is a difference in judged facial attractiveness among the different levels of upper incisor retraction in the repose profiles. There is no difference in judged facial attractiveness among the different levels of upper incisor retraction in the smiling profiles.

4. PARTIALLY REJECTED: There is a difference in the judged facial attractiveness between the orthodontic professionals and the laypersons in the repose profiles. There is no difference in the judged facial attractiveness between the orthodontic professionals and the laypersons in the smiling profiles.

\section{CLINICAL SIGNIFICANCE}

The public is becoming exceedingly aware of esthetics, and often evaluate their orthodontic treatment outcome based upon the improvement of their smile and overall enhancement of their facial appearance. Furthermore, the ongoing debate as to whether or not extractions harm the profile continues. This research favors the side that suggests that extraction therapy does not harm the profile, in either smiling or repose. It addition, the smiling profile was favored over the repose profile post-treatment, which suggests the importance of the smiling profile. Further research is necessary to help elucidate if there is a threshold for the retraction of the upper incisors, and the effect on facial beauty. Ultimately, a treatment decision taking into 
consideration the entire dentofacial complex, and not just the teeth should be made in conjunction with the patient after informed consent. 


\section{CHAPTER 6: SUMMARY AND CONCLUSIONS}

\section{SUMMARY}

The aim of this study was to determine if facial attractiveness is harmed in subjects having completed orthodontic treatment involving the extraction of four premolars both in repose and smiling when viewed in lateral profile. Another objective was to identify any impact upper incisor retraction has on facial attractiveness. Orthodontic professionals and laypersons judged the facial attractiveness of the pre-treatment and post-treatment repose and smiling profiles of 39 randomly selected subjects. Statistical analyses were performed for the variables for each photographed subject. Statistically significant differences were found within the repose data, but not the smiling data.

\section{CONCLUSIONS}

Based on the results of this study, the following conclusions have been reached:

1. Extraction therapy is not harmful to the repose profile or the smiling profile.

2. More subjects were judged to be more attractive post-treatment in smiling than repose.

3. Four premolar extraction made the profile more attractive in repose, whenever the incisors were retracted more than $2 \mathrm{~mm}$.

4. Orthodontists gave higher attractiveness ranking scores than laypersons in repose.

5. There are no differences between judged facial attractiveness and non-extraction vs. extraction therapy, orthodontic vs. layperson, or amount of retraction in smiling. 


\section{CHAPTER 7: RECOMMENDATIONS FOR FUTURE RESEARCH}

\section{RECOMMENDATIONS ON SAMPLE COLLECTION}

The study at hand could be improved by dividing the subjects into groups determined by the pretreatment overjet. The amount of pretreatment overjet does play a role in smile esthetics. Dividing the subjects into groups based on pretreatment overjet would allow for the effect of the type of treatment (four premolar extraction therapy versus non-extraction therapy) to be investigated with respect to each type of malocclusion. Using pretreatment overjet, rather than ANB values would be superior, because cephalometric numbers are determined by the cranial bases, and do not always reflect the real dental occlusion.

Additionally, including more orthodontists who are not trained in evaluating the smiling profile could potentially have a significant effect on the results of this study. This study aimed to investigate the judged facial attractiveness of extraction and non-extraction orthodontic treatment in repose and smiling. A stimulus for further research could be to use subjects of different ethnicities or ages to see if there are any differences in judged facial attractiveness with respect to these new variables.

\section{RECOMMENDATIONS OF METHODOLOGY}

This study could be enhanced by changing the methodology in which data was presented to the raters. Displaying the entire face in the assessment of facial esthetics simulates routine social interaction. However, doing so mitigates the impact the smile has on facial esthetics because other features may draw more attention to the rater. Restricting the photograph to just the region

of the mouth can lessen this effect. ${ }^{54}$ Boyles-Horan et al. previously concluded that developing a 
method to present profile photos to limit the effects of confounding variables such as hair, complexion, makeup, complexion, nose, chin, and other facial features would reduce variability when investigating judged facial attractiveness. ${ }^{55}$ Cropping the profile photos to depict the region from the bridge of the nose to menton eliminates many other facial features like hair, eyes, and makeup, from contributing to facial attractiveness. ${ }^{56}$ This change in methodology could allow the rater to focus more on position of the upper incisors. Lastly, Cheng and Wang make a point that smile esthetics are dynamic and difficult to measure. They continue to state that there is "no standard method of evaluation," and that "smiles are judged according to the balance of the whole face in actual life." ${ }^{, 57}$ Therefore, for further research, it is critical to obtain equal baseline characteristics of each of the subjects. Digital videos or 3D views of the smiles may be useful in obtaining reproducible and comprehensive photographs. 


\section{REFERENCES}

${ }^{1}$ Phillips C, Tulloch C, Dann C. Rating of facial attractiveness. Community Den Oral Epidemiol. 1992;20:213-220

${ }^{2}$ Ambrosio AR, Trevilatto PC, Sakima T, Ignácio SA, Shimizu RH. Correlation between morphology and function of the upper lip: a longitudinal evaluation. Eur J Orthod.

2009;31(3):306-13.

${ }^{3}$ Andrews, WA (2008) AP Relationship of the Maxillary Central Incisors to the Forehead in Adult White Females. The Angle Orthodontist: July 2008, Vol. 78, No. 4, pp. 662-669.

${ }^{4}$ Andrews LF AW. Syllabus of the Andrews orthodontic philosophy. U.S., 2001 (Ninth ed).

${ }^{5}$ Andrews, WA (2008) AP Relationship of the Maxillary Central Incisors to the Forehead in Adult White Females. The Angle Orthodontist: July 2008, Vol. 78, No. 4, pp. 662-669.

${ }^{6}$ Schlosser JB, Preston CB, Lampasso J. The effects of computer-aided anteroposterior maxillary incisor movement on ratings of facial attractiveness. Am J Orthod Dentofacial Orthop. 2005;127(1):17-24.

${ }^{7}$ Işiksal E, Hazar S, Akyalçin S. Smile esthetics: perception and comparison of treated and untreated smiles. Am J Orthod Dentofacial Orthop. 2006;129(1):8-16.

${ }^{8}$ Erian A, Shiffman MA. Advanced Surgical Facial Rejuvenation, Art and Clinical Practice. Springer; 2011.

${ }^{9}$ Farkas LG, Munro JR. Anthropometric Facial Proportions in Medicine. Springifled, Ill.: Charles C Thomas; 1987.

${ }^{10}$ Sarver DM, Ackerman JL. Evaluation of facial soft tissues. In: Proffit WR, ed. Contemporary Treatment of Facial Deformity. St. Louis, MO: Mosby; 2003.92-126.

${ }^{11}$ Proffit, W., Fields, H., \& Sarver, D. (2007). Contemporary orthodontics (4th ed.). St. Louis, Mo.: Mosby Elsevier.

${ }^{12}$ Proffit, W., Fields, H., \& Sarver, D. (2007). Contemporary orthodontics (4th ed.). St. Louis, Mo.: Mosby Elsevier.

${ }^{13}$ Sommersville JM, Sperry TP, Begole EA: Morphology of the submental and neck region, Int J Adult Orthod Orthogn Surg 3:97-106, 1988.

${ }^{14}$ Ellenbogen R, Karlin J: Visual criteria for success in restoring the youthful neck, Plast Reconstr Surg 66:826-837, 1980. 
${ }^{15}$ Peck S, Peck L. The gingival smile line. Angle Orthod. 1992; 62:91-100.

${ }^{16}$ Sarver DM, Ackerman JL. Evaluation of facial soft tissues. In: Proffit WR, ed. Contemporary Treatment of Facial Deformity. St. Louis, MO: Mosby; 2003.92-126.

${ }^{17}$ Smile esthetics: perception and comparison of treated and untreated smiles. Am J Orthod Dentofacial Orthop. 2005:8-16.

${ }^{18}$ Andrews LF. The six keys to normal occlusion. Am J Orthod. 1972;62(3):296-309.

${ }^{19}$ Andrews LF. The 6-elements orthodontic philosophy: Treatment goals, classification, and rules for treating. Am J Orthod Dentofacial Orthop. 2015;148(6):883-7.

${ }^{20}$ Andrews LF AW. Syllabus of the Andrews orthodontic philosophy. U.S, 2001(Ninth ed).

${ }^{21}$ Shammaa, A. Optimal Anteroposterior Position of Maxillary Incisors in Caucasian Males Viewed from a Smiling Profile. WVU Master Thesis. 2016.

${ }^{22}$ Tomblyn J. Facial Planes as Landmarks for Diagnosis and Treatment Planning. WVU Master Thesis. 2015.

${ }^{23}$ Andrews LF. The 6-elements orthodontic philosophy: Treatment goals, classification, and rules for treating. Am J Orthod Dentofacial Orthop. 2015;148(6):883-7.

${ }^{24}$ Lima APB, Conti ACCF, Filho LC, Cardoso MA, Almeida-pedrin RR. Influence of facial pattern in smile attractiveness regarding gingival exposure assessed by dentists and laypersons. Am J Orthod Dentofacial Orthop. 2019;155(2):224-233.

${ }^{25}$ Li Cao, Ke Zhang, Ding Bai, Yan Jing, Ye Tian, and Yongwen Guo (2011) Effect of maxillary incisor labiolingual inclination and anteroposterior position on smiling profile esthetics. The Angle Orthodontist: January 2011, Vol. 81, No. 1, pp. 121-129.

${ }^{26}$ Schlosser JB, Preston CB, Lampasso J. The effects of computer-aided anteroposterior maxillary incisor movement on ratings of facial attractiveness. Am J Orthod Dentofacial Orthop. $2005 ; 127: 24$.

${ }^{27}$ Stephens CK, Boley JC, Behrents RG, Alexander RG, Buschang PH. Long-term profile changes in extraction and nonextraction patients. Am J Orthod Dentofacial Orthop. 2005;128(4):450-7.

${ }^{28}$ Işiksal E, Hazar S, Akyalçin S. Smile esthetics: perception and comparison of treated and untreated smiles. Am J Orthod Dentofacial Orthop. 2006;129(1):8-16.

${ }^{29}$ Cordato M. Variation in torque expression. Am J Orthod Dentofacial Orthop 2004,126(1):18A. 
${ }^{30}$ A.H. Meyer, M.G. Woods, D.J. Manton. Maxillary arch width and buccal corridor changes with orthodontic treatment. Part 1: differences between premolar extraction and nonextraction treatment outcomes. Am J Orthod Dentofacial Orthop, 145 (2014), pp. 207-216.

${ }^{31}$ Bowman SJ, Johnston LE. The esthetic impact of extraction and nonextraction treatments on Caucasian patients. Angle Orthod. 2000;70(1):3-10.

${ }^{32}$ Bishara SE, Jakobsen JR. Profile changes in patients treated with and without extractions: assessments by lay people. Am J Orthod Dentofacial Orthop 1997;112:639-44.

${ }^{33}$ Almurtadha RH, Alhammadi MS, Fayed MMS, Abou-el-ezz A, Halboub E. Changes in Soft Tissue Profile After Orthodontic Treatment With and Without Extraction: A Systematic Review and Meta-analysis. J Evid Based Dent Pract. 2018;18(3):193-202.

${ }^{34}$ Lundström, Anders et al. The Frankfort horizontal as a basis for cephalometric analysis American Journal of Orthodontics and Dentofacial Orthopedics , Volume 107 , Issue 5 , 537 540

${ }^{35}$ Meiyappan N, Tamizharasi S, Senthilkumar KP, Janardhanan K. Natural head position: An overview. J Pharm Bioallied Sci. 2015;7(Suppl 2):S424-7.

${ }^{36}$ Moorrees CF, Kean MR. Natural head position: A basic consideration in the interpretation of cephalometric radiographs. Am J Phys Anthropol. 1958;16:213.

${ }^{37}$ Pereira A, Manzotti De-Marchi L, Scheibel P, Ramo A. Reproducibility of natural head position in profile photographs of children aged 8 to 12 years with and without the aid of a cephalostat. Dental Press J. Orthod. vol.15 no.1 Maringá Jan./Feb. 2010

${ }^{38}$ Lundstrom A, Lundstrom. Natural Head Position As A Basis For Cephalometric Analysis. Am J Orthod Dentofacial Orthop.1992 Mar;101(3):244-7.

${ }^{39}$ Cooke MS. Five-year reproducibility of natural head posture: a longitudinal study. Am J Orthod Dentofacial Orthop. 1990; 97: 489-494.

${ }^{40}$ Lundstrom A, Lundstrom F, Lebret LM, Moorrees CF. Natural head position and natural head orientation: basic considerations in cephalometric analysis. Eur J Orthod. 1995; 17: 111-120.

${ }^{41}$ Phillips C, Tulloch C, Dann C. Rating of facial attractiveness. Community Den Oral Epidemiol. 1992;20:213-220.

${ }^{42}$ Phillips C, Tulloch C, Dann C. Rating of facial attractiveness. Community Den Oral Epidemiol. 1992;20:213-220.

${ }^{43}$ Elder G. H. J. 1969. Appearance and education in marriage mobility. Am. Soc. Rev. 34, 519$53310.2307 / 2091961$

${ }^{44}$ Little AC, Jones BC, Debruine LM. Facial attractiveness: evolutionary based research. Philos Trans R Soc Lond, B, Biol Sci. 2011;366(1571):1638-59. 
${ }^{45}$ Foster EJ. Profile preferences among diversified groups. Angle Orthod 1973;43:34-40.

${ }^{46}$ Kokich VO, Kokich VG, Kiyak HA. Perceptions of dental professionals and laypersons to altered dental esthetics: asymmetric and symmetric situations. Am J Orthod Dentofacial 2006; 130: $131-151$.

${ }^{47}$ Barbosa de Lima AP, Conti ACCF, Filho LC, Cardoso MA, Almeida-Pedrin RR. Influence of facial pattern in smile attractiveness regarding gingival exposure assessed by dentists and laypersons. Am J Orthod Dentofacial Orthop. 2019;155(2):224-233.

${ }^{48}$ Giron de Velasco J, De la Cuadra P, Urizar G. The influence of maxillary incisor torque on the esthetic perception of the smile. Int J Esthet Dent. 2017;12(3):378-395.

${ }^{49}$ Pancherz H, Bjerklin K, Hashemi K. Late adult skeletofacial growth after adolescent Herbst therapy: a 32-year longitudinal follow-up study. Am J Orthod Dentofacial Orthop. 2015;147(1):19-28.

${ }^{50}$ Bowman SJ, Johnston LE. The esthetic impact of extraction and nonextraction treatments on Caucasian patients. Angle Orthod. 2000;70(1):3-10.

${ }^{51}$ Foster EJ. Profile preferences among diversified groups. Angle Orthod 1973;43:34-40.

${ }^{52}$ Lauria A, Rodrigues DC, De medeiros RC, Moreira RW. Perception of oral and maxillofacial surgeons, orthodontists and laypersons in relation to the harmony of the smile. J Craniomaxillofac Surg. 2014;42(8):1664-8.

${ }^{53}$ Phillips C, Tulloch C, Dann C. Rating of facial attractiveness. Community Den Oral Epidemiol. 1992;20:213-220.

${ }^{54}$ Lima APB, Conti ACCF, Filho LC, Cardoso MA, Almeida-pedrin RR. Influence of facial pattern in smile attractiveness regarding gingival exposure assessed by dentists and laypersons. Am J Orthod Dentofacial Orthop. 2019;155(2):224-233.

${ }^{48}$ Boyles-Horan M, Ngan P, Martin C, Weaver B. Identifying the esthetically optimal AP position of maxillary incisors in Caucasian females. WVU Master Thesis 2018.

${ }^{56}$ Stephens CK, Boley JC, Behrents RG, Alexander RG, Buschang PH. Long-term profile changes in extraction and nonextraction patients. Am J Orthod Dentofacial Orthop. 2005;128(4):450-7.

${ }^{57}$ Cheng HC, Wang YC. Effect of nonextraction and extraction orthodontic treatments on smile esthetics for different malocclusions. Am J Orthod Dentofacial Orthop. 2018;153(1):81-86. 


\section{APPENDIX A - IRB APPROVAL LETTER}

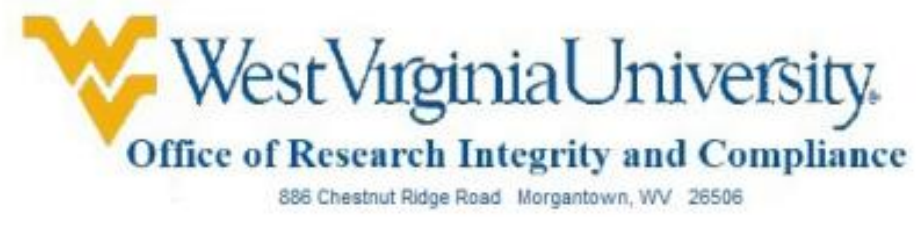

Approval of Human Research Protocol

$07 / 09 / 2018$

To: Peter Ngan

From: WVU Office of Research Integrity \& Compliance

Protocol Type: Expedited

Approval Date: 07/09/2018

Submission Type: Initial

Expiration Date: 07/08/2019

Funding: N/A

WVU Protocol \#: 1805113206

Protocol Title: Judged Facial Attractiveness of Extraction and Non-Extraction Orthodontic Treatment in Repose and Smiling

The West Virginia University Institutional Review Board has reviewed and granted your request for approval of Expedited protocol 1805113206, in accordance with the Federal regulations 45 CFR 46, 21

CFR 50, and 21 CFR 56 (when applicable). Additional details concerning the review are below:

- Category 5. Research involving materials (data, documents, records, or specimens) that have been collected, or will be collected solely for nonresearch purposes (such as medical treatment or diagnosis).

- Category 6. Collection of data from voice, video, digital, or image recordings made for research purposes.

- Category 7. Research on individual or group characteristics or behavior (including, but not limited to, research on perception, cognition, motivation, identity, language, communication, cultural beliefs or practices, and social behavior) or research employing survey, interview, oral history, focus group, program evaluation, human factors evaluation, or quality assurance methodologies. [NOTE: Some research in this category may be exempt from the DHHS regulations for the protection of human subjects. See Exempt Categories and 45 CFR 46.101(b)(2) and (b)(3). This listing refers only to research that is not exempt.] 
The following documents were reviewed and approved for use as part of this submission. Only the documents listed below may be used in the research. Please access and print the files in the Notes \& Attachments section of your approved protocol.

- Consent Form PDF.pdf

- Survey (1) UPDATED.docx

- HIPAA Waiver UPDATED.docx

- 2018_07_03_11_32_11.pdf

\section{WVU IRB approval of protocol 1805113206 will expire on 07/08/2019.}

If any study related activities are to continue beyond the expiration date, a renewal application should be submitted no later than four (4) weeks prior to the expiration date. It is your responsibility to submit your protocol for continuing review.

Once you begin your human subjects research, the following regulations apply:

1. Unanticipated or serious adverse events and/or side effects encountered in this research study must be reported to the IRB within five (5) days using the Notify IRB action in the electronic protocol.

2. Any modifications to the study protocol or informed consent form must be reviewed and approved by the IRB prior to implementation. These modifications should be submitted as an amendment.

3. You may not use a modified informed consent form until it has been reviewed and approved by the WVU IRB. Only consent forms with the WVU+ke watermark may be used to obtain informed consent from participants.

The Office of Research Integrity and Compliance will be glad to provide assistance to you throughout the research process. Please feel free to contact us by phone, at 304.293 .7073 or by email at IRB@mail.wvu.edu.

Sincerely,

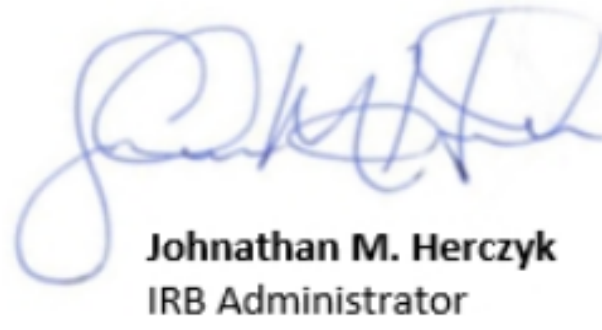




\section{APPENDIX B - VISUAL ANALOGUE SCALE SURVEY SAMPLE}

\section{Survey}

Instructions: You will be shown PowerPoint slides of 39 nonsmiling and 39 smiling images (2 photos per slide) for 15 seconds each.

Please evaluate the attractiveness of the profiles, particularly the area of the mouth, and mark a vertical line along the scales below to represent where each photo falls on the scale from "not at all attractive" to "very attractive." Two scales have been provided for each slide to evaluate the two photos presented.

Please also answer the following 2 questions by circling which applies to you:

\section{1) I am a WVU First Year Dental Student I am WVU Orthodontic faculty/resident}

2) Male Female

\section{NONSMILING PHOTOS}

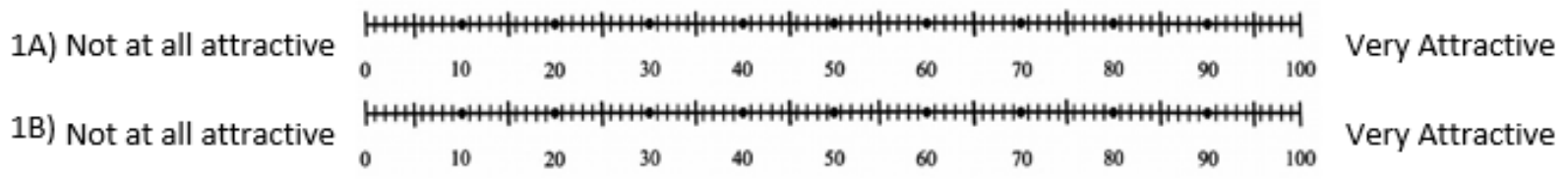

2A) Not at all attractive

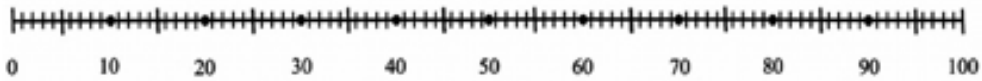

Very Attractive

2B) Not at all attractive

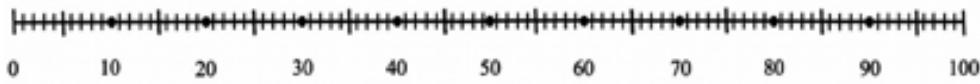

Very Attractive

3A) Not at all attractive

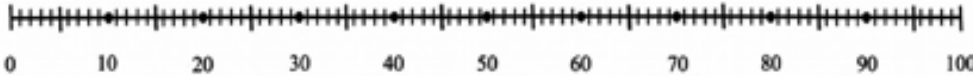

3B) Not at all attractive

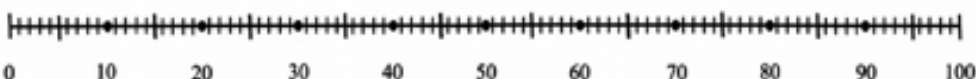

Very Attractive

Very Attractive

39A) Not at all attractive

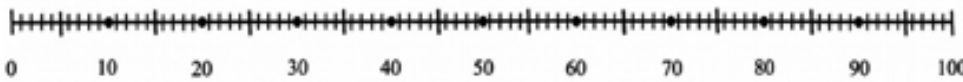

Very Attractive

39B) Not at all attractiv

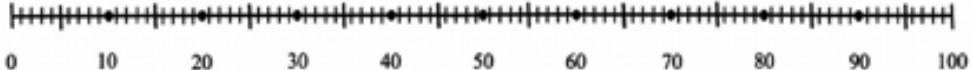

Very Attractive 


\section{SMILING PHOTOS}

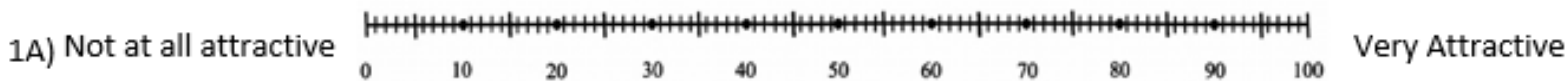

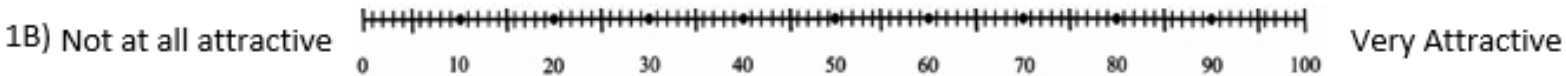

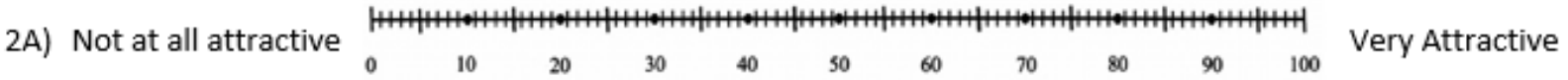

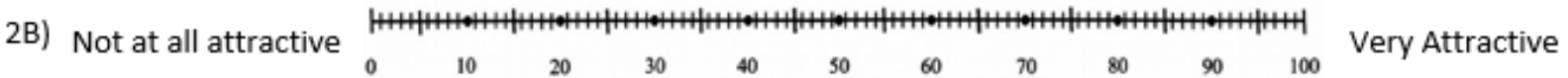

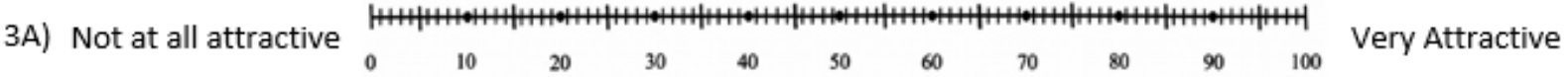

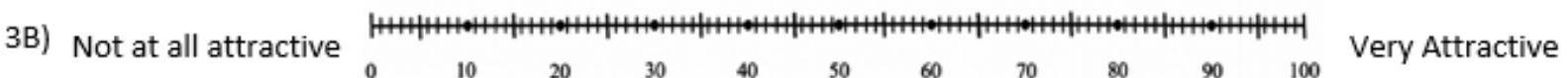

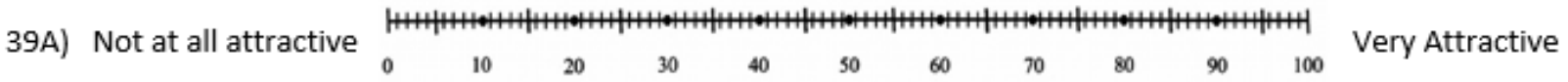

39B) Not at all attractive $\begin{array}{cccccccccc}\text { 30 } \\ 0\end{array}$ 